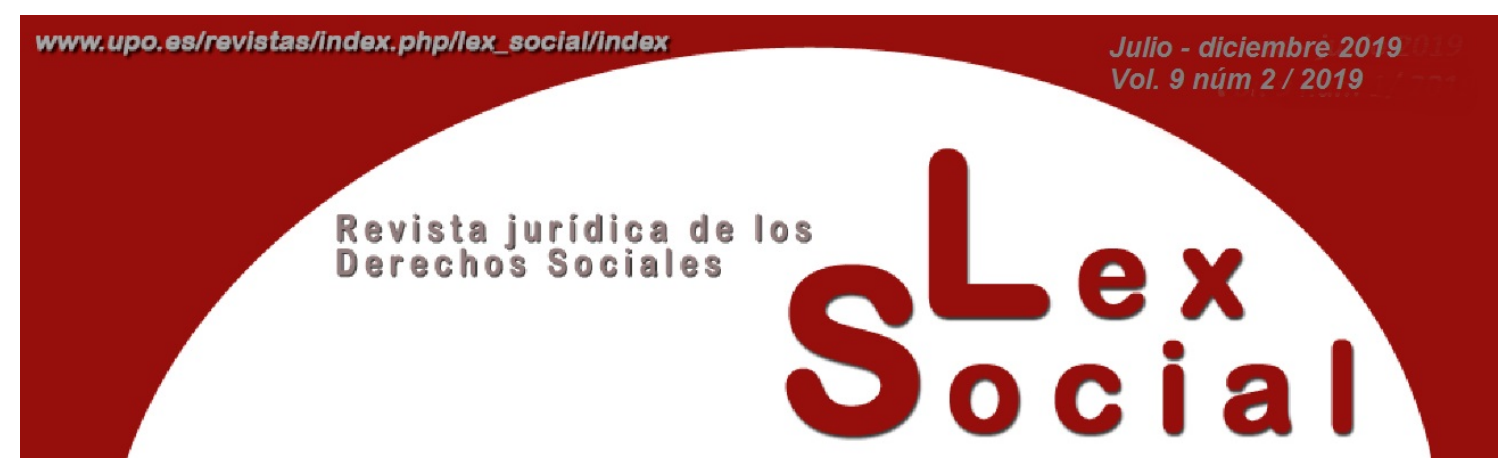

\title{
CARACTERÍSTICAS PERSONALES Y CONDICIONES JURÍDICO-LABORALES DEL EMPLEO DOMÉSTICO EN ESPAÑA: ESTUDIO A TRAVÉS DE LOS MICRODATOS DE LA ENCUESTA DE POBLACIÓN ACTIVA
}

\author{
PERSONAL CHARACTERISTICS AND LEGAL-LABOR \\ CONDITIONS OF DOMESTIC EMPLOYMENT IN SPAIN: STUDY \\ THROUGH THE MICRODATA OF THE LABOUR FORCE SURVEY.
}

LUIS GÓMEZ RUFIÁN

Universidad Carlos III de Madrid

Artículo recibido el 16 de mayo de 2019

Artículo aceptado el 27 de mayo de 2019

\begin{abstract}
RESUMEN
El presente trabajo constituye la primera parte de un doble estudio jurídicoeconómico sobre el empleo doméstico en España. Concretamente, en ésta se aborda en detalle las características personales (edad, sexo, nacionalidad, formación, etc.) y jurídico-laborales (temporalidad, parcialidad, antigüedad, jornada efectiva, etc.) de los diferentes tipos de empleo doméstico. Ello se ha realizado mediante una explotación pormenorizada de los microdatos de la Encuesta de Población Activa.
\end{abstract}

Palabras clave: empleo doméstico; informalidad; sexo; nacionalidad; temporalidad; parcialidad; jornada efectiva.

Abstract 
The present work constitutes the first part of a double legal-economic study about domestic employment in Spain. Specifically, this part analyzes in detail the personal (age, sex, nationality, training, etc.) and legal-labor (temporality, bias, seniority, effective working day, etc.) characteristics of the different types of domestic employment. This has been done through a detailed exploitation of microdata from the Labour Force Survey.

\section{KEYWORDS:}

domestic employment; informality; gender; nacionality; temporary empleoyment; part-time employment; effective work day.

SUMARIO.

1. INTRODUCCIÓN.

2. APUNTE METODOLÓGICO: LA TIPOLOGÍA DEL TRABAJO DOMÉSTICO.

3. EVOLUCIÓN DEL VOLUMEN TOTAL DE EMPLEO Y DEL GRADO DE INFORMALIDAD.

4. CARACTERÍSTICAS PERSONALES.

4.1 Sexo.

4.2 Edad (y sexo).

4.3 Nacionalidad (y sexo).

4.3.1 La cuestión del país de nacimiento.

4.3.2 Trabajadoras nacionales, extranjeras y el empleo doméstico ante la situación de su hogar.

4.4 Formación (y nacionalidad).

5. RÉGIMEN JURÍDICO-LABORAL.

5.1 Temporalidad y antigüedad.

5.2 Parcialidad, jornada semanal efectiva y absentismo por siniestralidad.

5.3 Régimen laboral y nacionalidad.

5.4 Distribución ocupacional.

6. CONCLUSIONES SUMARIAS. 


\section{INTRODUCCIÓN.}

El objeto de este estudio ${ }^{1}$ es realizar un análisis detallado y en profundidad del empleo doméstico en España desde un punto de vista laboral, es decir, referente a los ocupadas (ocupadas, esencialmente) que, a su vez, se proyecta en dos direcciones complementarias: por lado, conocer las características personales de las trabajadoras de esta sección de actividad tan sumamente particular, lo que obliga a analizar variables tales como el grado de feminización, la edad, la nacionalidad, la situación económica en lo relativo a ingresos de sus hogares como determinante de la decisión o no de participar en este sector o el nivel formativo que poseen, así como las interrelaciones pertinentes entre este conjunto de variables; por el otro, desde un punto de vista propiamente jurídico-laboral, se traza el análisis, también detallado y en profundidad de cuestiones tan centrales como la tasa de temporalidad (incluyendo la duración de los contratos) y parcialidad (con la consecuente referencia a la involuntariedad en la misma), los niveles de antigüedad y de extensión de la jornada efectiva, absentismo por enfermedad y distribución ocupacional, y todo ello teniendo en cuenta que en varias de estas variables se han realizado cruces con las de tipo personal, tales como el sexo o la nacionalidad, evidenciando las situaciones de especial precariedad e inestabilidad que caracterizan a un sector sociolaboralmente.

Todo ello, además, se aborda partiendo de la realización de una panorámica sobre el trabajo doméstico en términos de evolución agregada y, además, diferenciando entre la distinta tipología con que éste puede manifestarse en el mercado de trabajo, cuestión que se aborda en el epígrafe inmediatamente posterior a esta introducción.

Expuesto el objeto, la estructura y la introducción metodológica, cabe señalar, incidiendo en esta última cuestión, que se trata éste de un trabajo eminentemente cuantitativista, es decir, basado en la explotación de los datos estadísticos existentes al respecto de la información que se desea analizar y que constituye su objeto de estudio. En ese sentido, el estudio se ha construido a través del estudio en profundidad de los microdatos de la Encuesta de Población Activa (en adelante, EPA), los cuales, a efectos académicos, poseen un nivel de desagregación superior a los que habitualmente se ponen a disposición del público por parte del INE.

\footnotetext{
1 Desearía agradecer los comentarios realizados al presente trabajo por las profesoras María Gema Quintero Lima, Magdalena Diaz Gorfinkel y Elisenda Moreno Ferragut, profesoras, respectivamente, del Departamentos de Derecho Social e Internacional Privado, Ciencias Políticas y Sociología y Estadística de la Universidad Carlos III de Madrid.
} 


\section{APUNTE METODOLÓGICO: LA TIPOLOGÍA DEL TRABAJO DOMÉSTICO.}

La necesidad de establecer una categorización o clasificación entre diferentes formas de empleo doméstico radica en la constatación de que éste, en realidad, constituye un fenómeno poliédrico, con muchísimas aristas desde el punto de vista no sólo económico y jurídico, sino, especialmente, funcional y sociológico. Así, para poder abarcar analíticamente todas las variantes de empleo doméstico que, por su especial naturaleza, brotan cuando se comienza a profundizar en la investigación en la materia y, se ha partido de intentar identificarlas y aislarlas en las bases de datos sobre las que se realiza el trabajo con el objetivo de convertirlas en el objeto de estudio. En ese sentido, es clave el papel del trabajo interno o no interno, el hecho de que el empleo doméstico pueda constituir un segundo empleo -normalmente en el ámbito del círculo personalque ayude a complementar las rentas depauperadas de un empleo principal, los casos abundantemente conocidos en los que se compaginan varios empleos de tipo doméstico mediante la limpieza y/o cuidado de niños en varios hogares, etc. De esta manera, se ha podido construir la siguiente clasificación según tipo de empleo doméstico:

\begin{tabular}{|c|c|c|}
\hline & Trabajo principal & Trabajo secundario \\
\hline Tipo 1 & ED & - \\
\hline Tipo 2 & ED & Otros (pero no ED) \\
\hline Tipo 3 & ED & ED \\
\hline Tipo 4 & Cualquiera & ED \\
\hline Tipo 5 & INTERNAS & - \\
\hline
\end{tabular}

Por tanto, dicho ahora desde un punto de vista más técnico, la idea de partida ha sido aislar las diferentes tipologías en función de si los empleados -en realidad, las empleadas como luego se verá- utilizaban el trabajo doméstico en los siguientes dos sentidos: 1) como su laboral central y específica o como como un complemento a otro tipo de actividades, para así diferenciar trabajadoras en sentido estricto de trabajadoras en pluriempleo (y que, a su vez, podían tomar el empleo doméstico como secundario o, por el contrario, necesitaban de uno secundario para complementar sus ingresos dada la precariedad del doméstico incluso cuando es el principal); y 2) conocer, sobre el global, 
el peso del empleo del empleo doméstico que se realiza en régimen de interinidad en los hogares.

Los resultados arrojan que el predominio lo ostenta las trabajadoras que señalan que sólo poseen un empleo principal y que éste es el doméstico junto a una cierta relevancia de aquellas que, para el desarrollo del mismo, se encuentran internas en los hogares. No obstante, atendiendo a la psicología de la respuesta al cuestionario de la EPA, es muy probable, aunque imposible de calcular, que buen número de las trabajadoras que señalan tener sólo el empleo doméstico como principal no lo desarrollen en un único hogar (razón ésta -la de prestar servicios en distintos hogares- por la cual, en la clasificación se integró la diferencia entre trabajo “principal” y "secundario”). Es decir, se trataría de casos en los que la trabajadora entiende que la sólo realiza una actividad el empleo doméstico- integrada, sin embargo, por la ejecución, en términos agregados, de numerosas tareas en más de un hogar y que el realizarlas en esa pluralidad no altera su respuesta en tanto en todos ellos es empleada doméstica. Se explicaría así, por tanto, la baja presencia de las trabajadoras de tipo 3.

Así, puede considerarse que esta categorización interna de la división 97 de la CNAE-09 permite que el estudio a realizar no quede a un nivel puramente superficial cual habría sido estudiar, únicamente, el total de dicha división.

No obstante, como es lógico a tenor de estos resultados, los dos subgrupos sobre los que se centrará esencialmente el análisis serán, junto al agregado total, los de tipo 1 y 5 pues ambos, respectivamente, representan en promedio para el periodo analizado en torno al 86,1\% y al 8,8\% de dicho agregado.

En cualquier caso, uno de los primeros elementos más relevantes del análisis que puede apuntarse ya es el de que este tipo de empleo ha llegado a rozar los 800.000 ocupados coincidiendo justo con el periodo anterior al inicio de la crisis económica. Concretamente, aunque los datos sobre empleo se analizarán con profusión en los siguientes puntos, su máximo de empleo se registró en el primer trimestre de 2010, alcanzando los 762.783 ocupados; por el contrario, su mínimo se dio en el segundo de 2015, con 616.941 ocupados (caída del -19,12\%). 

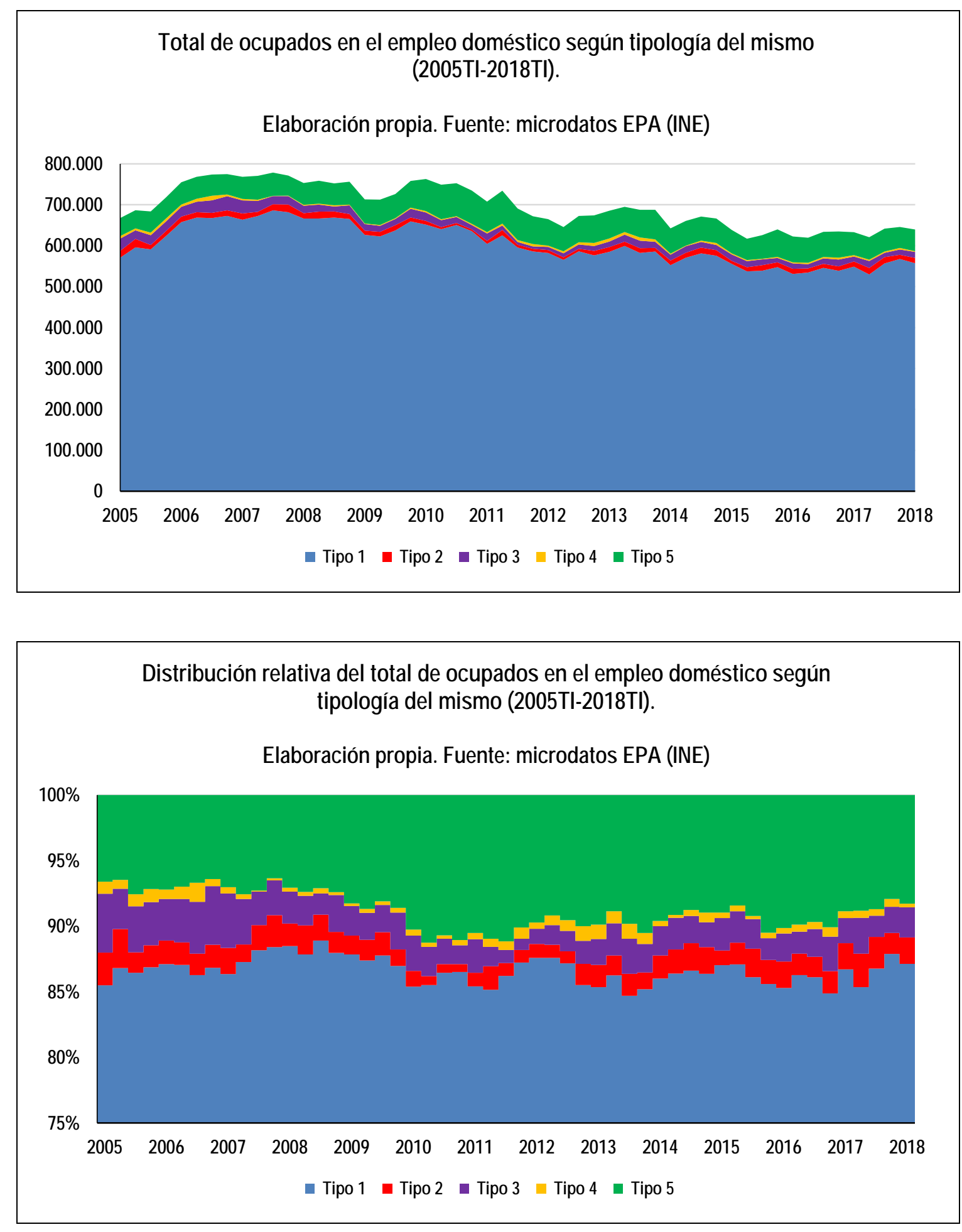


\section{EVOLUCIÓN DEL VOLUMEN TOTAL DE EMPLEO Y DEL GRADO DE INFORMALIDAD.}

Comenzando por su evolución desde el inicio de la recesión, paradójicamente a pesar de su clara precariedad, el empleo doméstico poseyó inicialmente una resistencia mayor a la misma en comparación al agregado de la economía. Sin embargo, sufre un colapso entre 2014 y 2015 -precisamente los años del inicio de la recuperación- traducido, como se señaló anteriormente, en una caída del $-19,12 \%$ en el segundo trimestre de 2015 en términos de trabajadores ocupados y del $-22,73 \%$ en términos de horas efectivamente trabajadas. Dicha tendencia, que probablemente pueda tener su causa, a pesar de la recuperación, en el agotamiento de ciertas rentas familiares dedicadas a contratar estos servicios, sólo comenzaría a revertirse, y muy lentamente, a partir de finales de 2017. En consecuencia, ello ha llevado a que su peso sobre el total de la ocupación haya caído de sus máximos del 4,08 y 4,04 en 2010 y 2013, respectivamente, al 3,4\% en 2018.

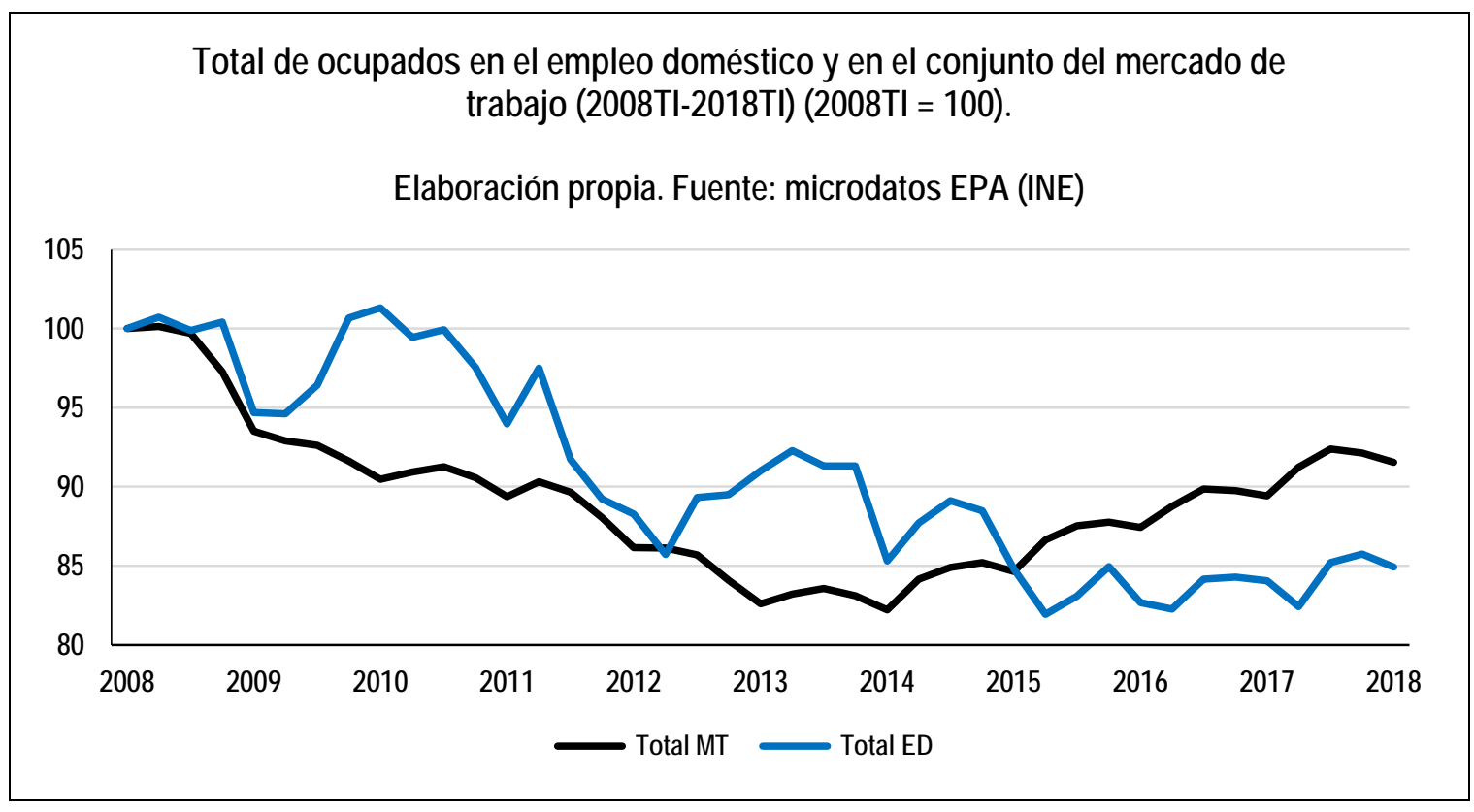



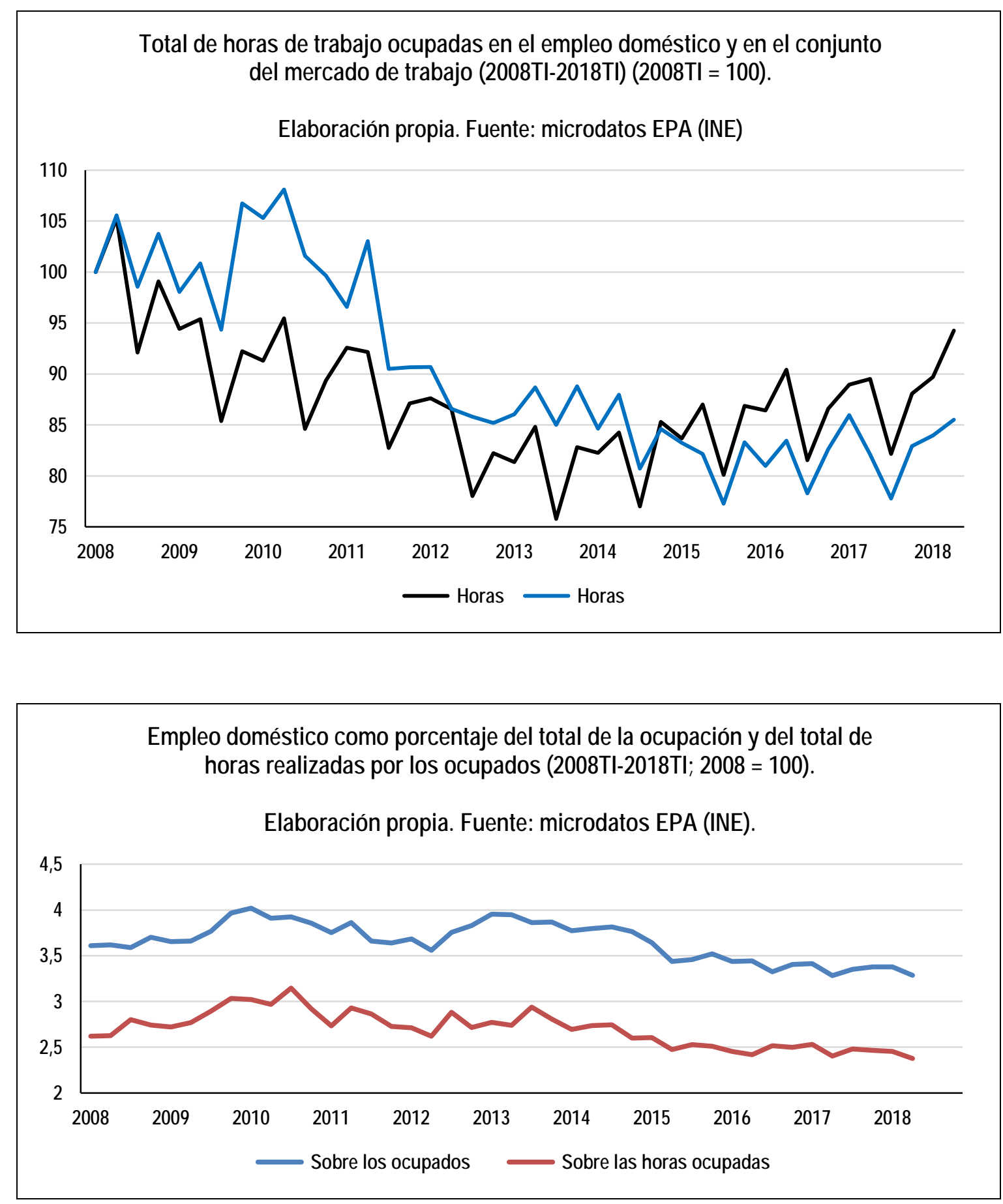

Por todos es conocido, a su vez, que éste es uno de los ámbitos de actividad en que con mayor intensidad el trabajo se realiza en condiciones paralelas a la legalidad o sin cobertura de la misma, lo que agrava el ya de por sí desproporcionado poder de disposición de los empleadores. Así, posee una extraordinaria informalidad manifestada porcentajes afiliación a la Seguridad Social que oscilan entre el 43,33\% de 2008 y el $75,90 \%$ de 2017. No obstante, aunque una cuarta parte de los trabajadores del sector siga en situación de informalidad, sí que se aprecian dos tendencias en cuanto al cambio 
normativo referido al tratamiento de este tipo de empleo desde el ámbito de la Seguridad Social operado en 2010: por un lado, que el mismo generó importantes incentivos para la el afloramiento y regularización de un amplio montante de trabajadoras del sector; y, por el otro, que, no obstante, dicho impulso apenas duró algo más de los dos años iniciales de vigencia del nuevo régimen de Seguridad Social, pues ya desde 2013 pero finalmente desde 2014, se estanca el porcentaje de trabajadoras regularizadas. Igualmente, ha de tenerse en cuenta que el número de afiliadas a la Seguridad Social aumentó, antes y después del cambio normativo, desde el entorno de las 340.000 al del de las 470.000, el peso de éstas sobre el total -y, por ende, el porcentaje de la regularización- tuvo como uno de sus factores incrementales adicionales la propia caída de empleo global que ya se ha comentado que ha sufrido el sector durante la crisis.

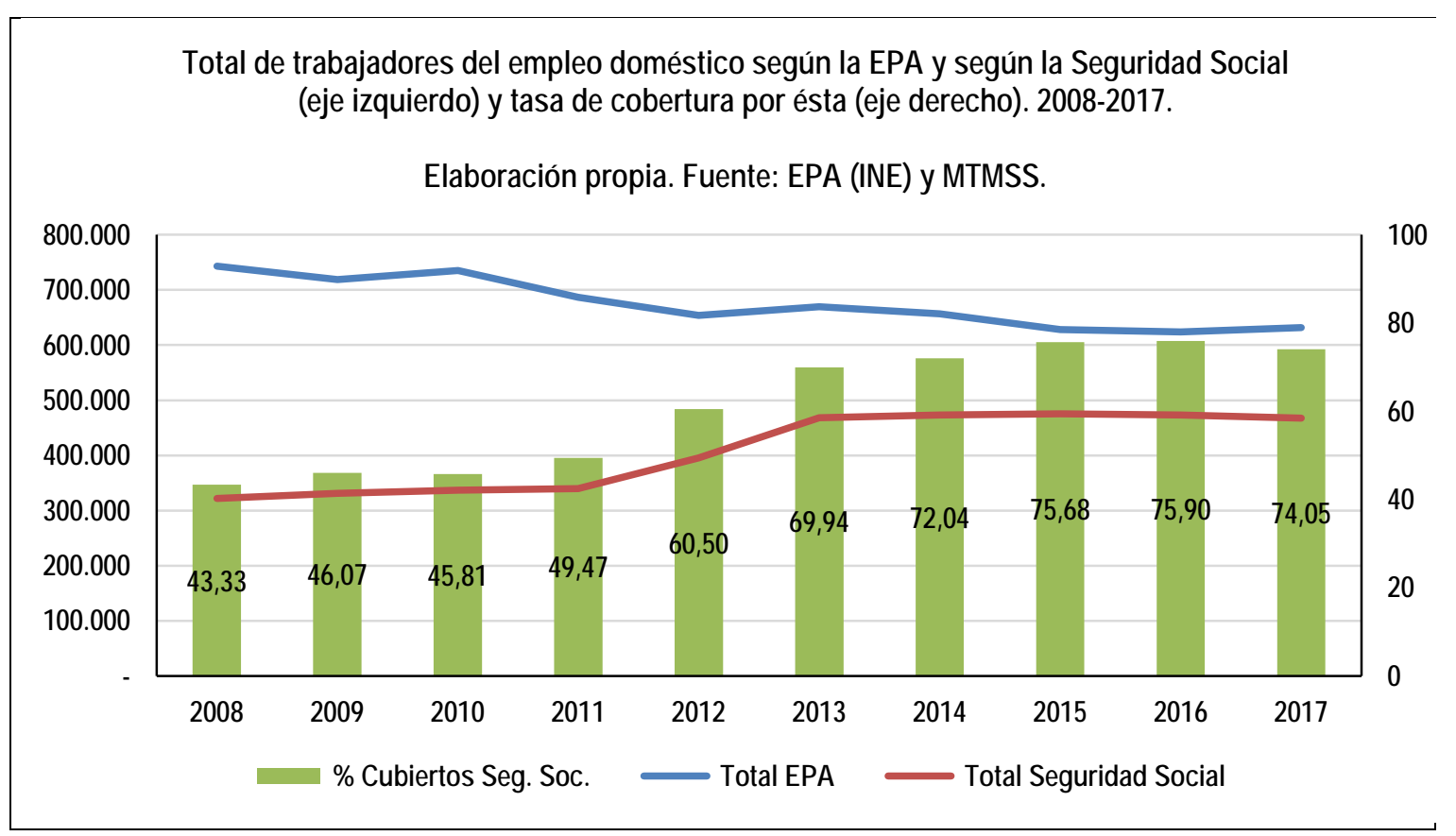

\section{CARACTERÍSTICAS PERSONALES.}

\subsection{Sexo.}

La otra gran característica del sector, cual es su conocido elevadísimo grado de feminización, se manifiesta en que los niveles de ocupación del mismo realizados por varones sólo hayan comenzado a notarse como consecuencia de la crisis económica, si bien sin llegar a superar el 15\% para el Tipo 1 ni apenas el 5\% para el Tipo 5. No obstante, tal y como puede apreciarse, esta entrada de trabajadores masculinos al empleo doméstico coincide con el inicio de la recesión, de modo que este sector también actuaría, aunque con mucha menos intensidad, como cierto ámbito de auxilio 
laboral para los varones ante la caída del empleo o de las rentas asociadas al mismo, rompiendo la concepción de tradicional rechazo masculino hacia este sector. No obstante, como luego se verá, el tipo de funciones realizadas por hombres y mujeres incluso dentro de esta misma sección de actividad dista de ser similar. En ambos casos, es decir, para el Tipo 1 y para al Tipo 5, la caída en el grado de feminización oscila alrededor de 6 a 7 puntos.

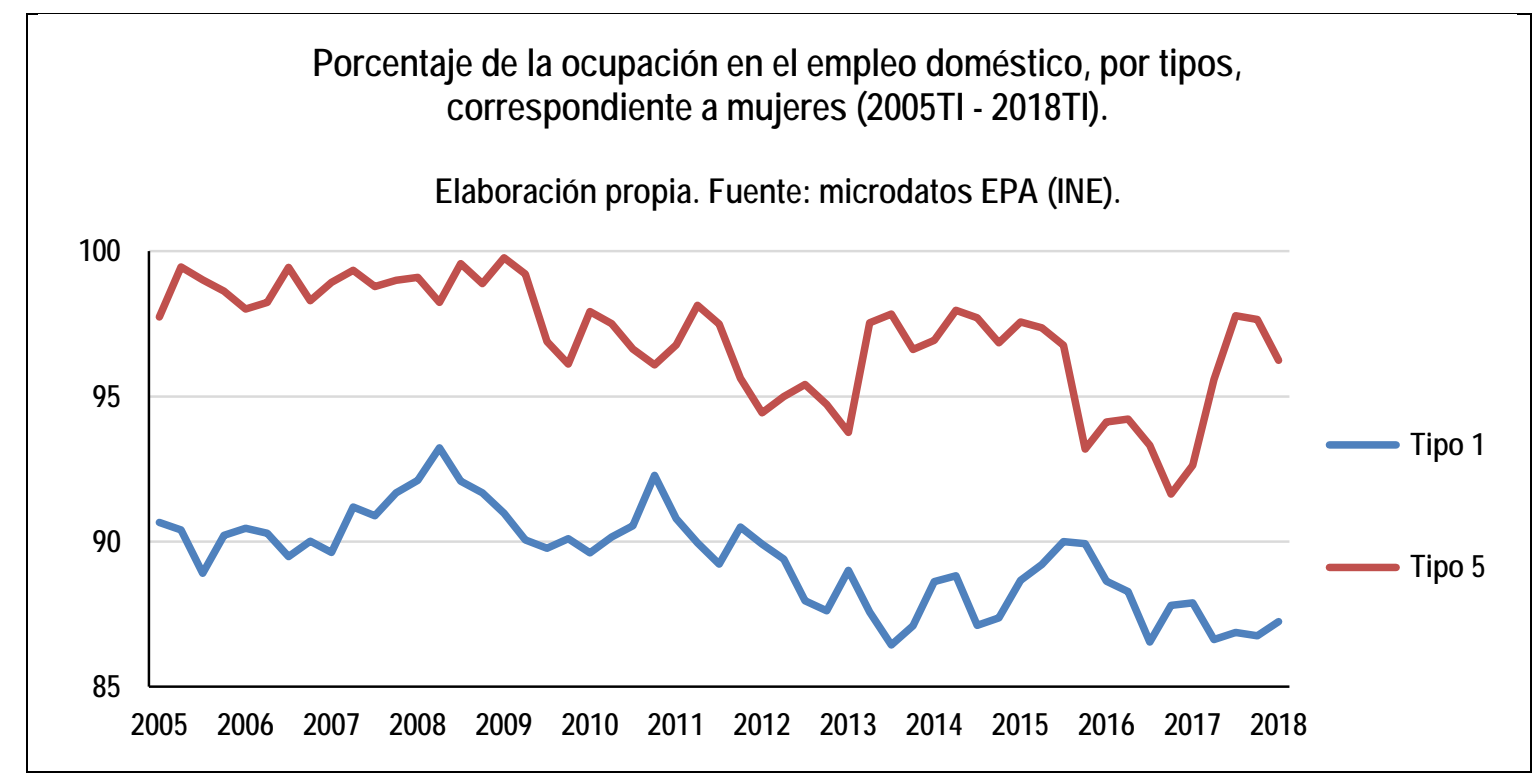

\subsection{Edad (y sexo).}

En cuanto al cruce sexo y edad (además del tipo de empleo doméstico), a excepción del empleo Tipo 1 masculino, los estratos bajos de edad han perdido peso hasta la casi desaparición de los mismos en el sector en favor de los de edad más avanzada, lo que implica que el mismo ha podido ser receptor de trabajadoras que ya no se encontraban en activo pero que, ante la situación económica, y dada la posible experiencia en el mismo en etapas pasadas o, sencillamente, en sus hogares, han encontrado en éste una vía de ingresos.

Cabe señalar que no se adjuntan datos para el empleo masculino del Tipo 5 ya que el bajo número de trabajadores presentes en el empleo doméstico en régimen interno impedía construir una serie de representatividad suficiente para el conjunto de estratos expuestos. 


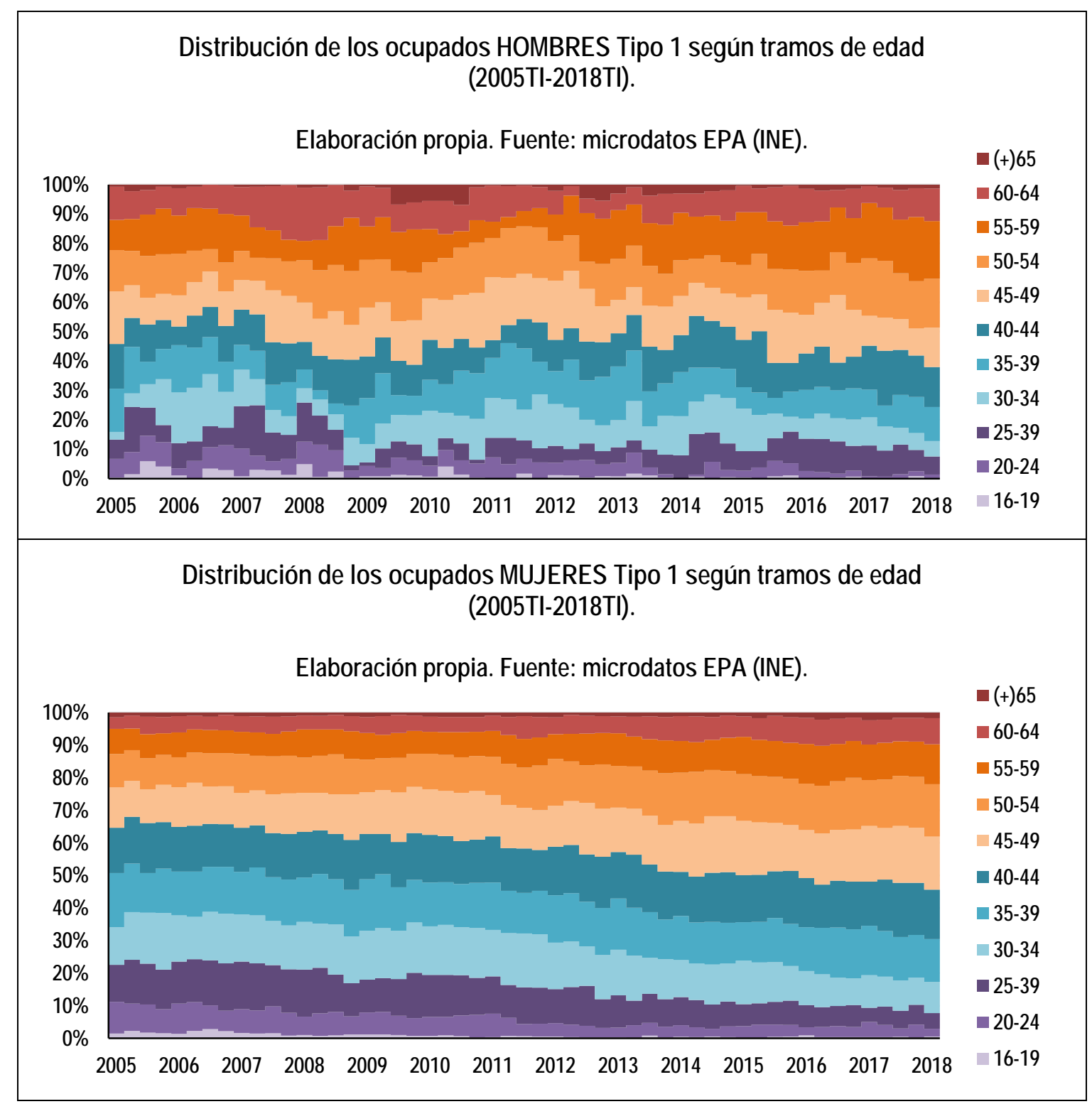




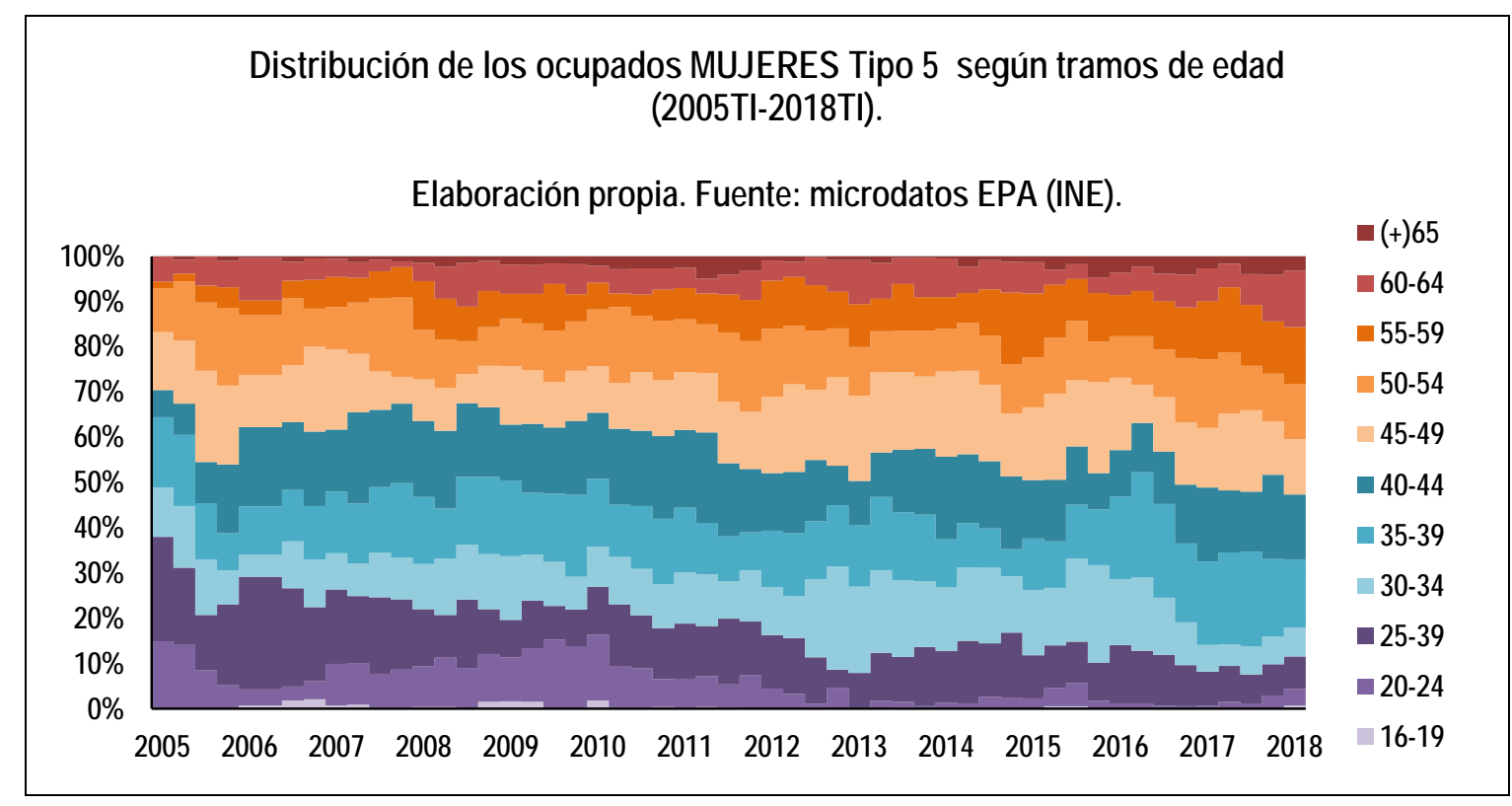

\subsection{Nacionalidad (y sexo).}

\subsubsection{La cuestión del país de nacimiento.}

Junto a la informalidad y la feminización, la tercera característica esencial de este tipo de empleo es el nivel en que éste viene siendo realizado, como es bien conocido, por mujeres nacidas fuera de España. Así, pasa a abordarse ahora la presencia en la ocupación del sector nacidos o no en España, debiendo puntualizarse que este criterio el del país de nacimiento- se utilizará sólo en este punto, mientras que en los restantes en que se aborde la nacionalidad, será esta como tal el criterio adoptado, computándose entonces a las personas nacidas fuera de España que, con el paso del tiempo, adquirieron la nacionalidad española.

Ello especialmente en el empleo de Tipo 5 (internas), donde su presencia se acercaba a valores próximos al 100\% hasta el inicio de la recesión, mientras que ara el Tipo 1 (ordinario), la presencia de nacidos en el extranjero superaba el 50\%. Cabe destacar que, en lo relativo a este Tipo 1, tan sólo el $20 \%$ de los trabajadores varones eran nacidos fuera de España, lo que denota un fuerte grado de rechazo a los trabajadores varones extranjeros en cuanto a la encomienda de estas actividades, fenómeno justamente a la inversa de lo que ocurre en el caso de las mujeres. Por tanto, éste sector venía a ser visto en buena medida como subsidiario para los nacionales españoles hasta el recrudecimiento de la situación socioeconómica

Analizando estas cuestiones desde una perspectiva dinámica, en ambos tipos de empleo doméstico se produce, en consonancia con los datos expuestos en los puntos precedentes, un aumento de la presencia de trabajadoras nacidas en España en detrimento de las tradicionales extranjeras: así ocurre en el caso de las internas (Tipo 5) 
desde 2009 y en las ordinarias (Tipo 1) desde 2010. Así, parecería haber una suerte de sustitución en el origen de los receptores de este tipo de empleo, lo cual, desde el punto de vista del empleador, podría venir a reflejar cierto prejuicio en el sentido de aceptar que estas labores sean realizadas por trabajadoras extranjeras cuando las mismas no resultan atractivas para los y las nacionales del país, pero prefieren a éstos y éstas cuando los mismos deciden incorporarse al sector como mano de obra. Este punto será desarrollado con más detenimiento en la parte final de este subepígrafe, donde la situación de las empleadas doméstica españolas se analiza desde el punto de vista de la situación de sus hogares familiares.

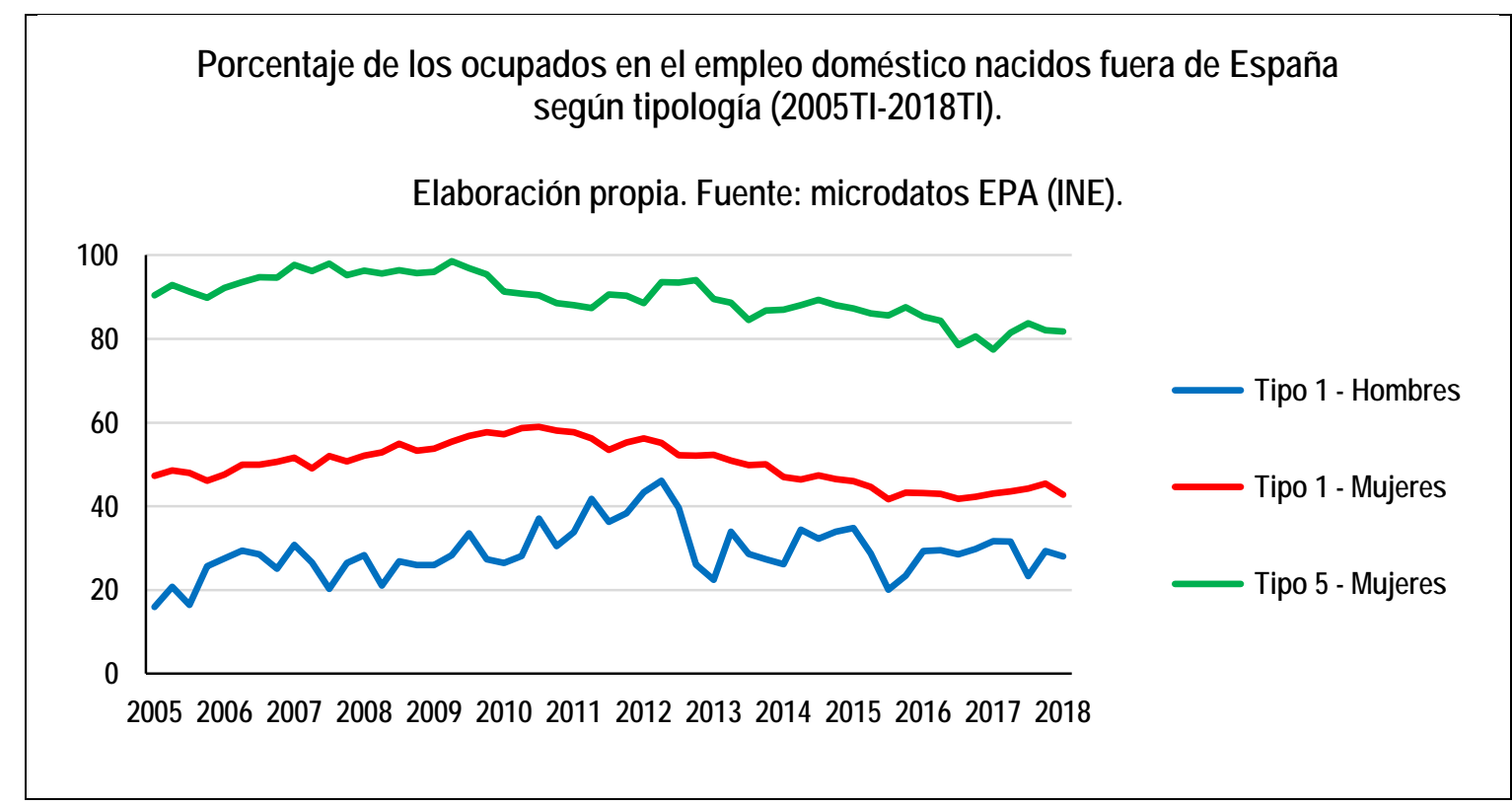

Entrando a evaluar el lugar de origen de las trabajadoras extranjeras en el sector, la tipología de lugares de nacimiento de los trabajadores se reveló tan inmensa en el estudio, que se ha decido tomar como países de origen relevante únicamente aquellos que, agregando el total de todos los ocupados a lo largo de la serie histórica de los trimestres analizados, superaran el 3\% del total al final de la misma (evitando así saltos y irregularidades constantes en la serie que imposibilitarían su análisis). Aplicando el criterio tanto a empleo doméstico Tipo 1 como al Tipo 5, los países que superan este requisito para ambos tipos son: Bolivia, Colombia, Ecuador, Filipinas, Honduras, Marruecos, Paraguay, Perú, Rep. Dominicana, Rumanía y Ucrania así como, además para el Tipo 5 (internas), Nicaragua. En ambos, casos, suman entre el $80 \%$ y el $90 \%$ de los ocupados para todo el periodo analizado de entre todas las nacionalidades.

Una vez señalado lo anterior, cabe mencionar algunas tendencias de interés en este sentido: por ejemplo, el fuerte peso de Bolivia en ambos tipos de empleo, hegemónico en el caso de las internas; en cuanto a los lugares de origen que progresivamente han ido 
perdiendo peso destacarían Ecuador para ambos tipos de empleo o Rumanía para el caso de las internas; a la contra, en los casos de Paraguay para ambos tipos, Filipinas para el segundo o, en menor medida, Ucrania también para ambos, su peso ha aumentado en la presencia relativa en el sector.

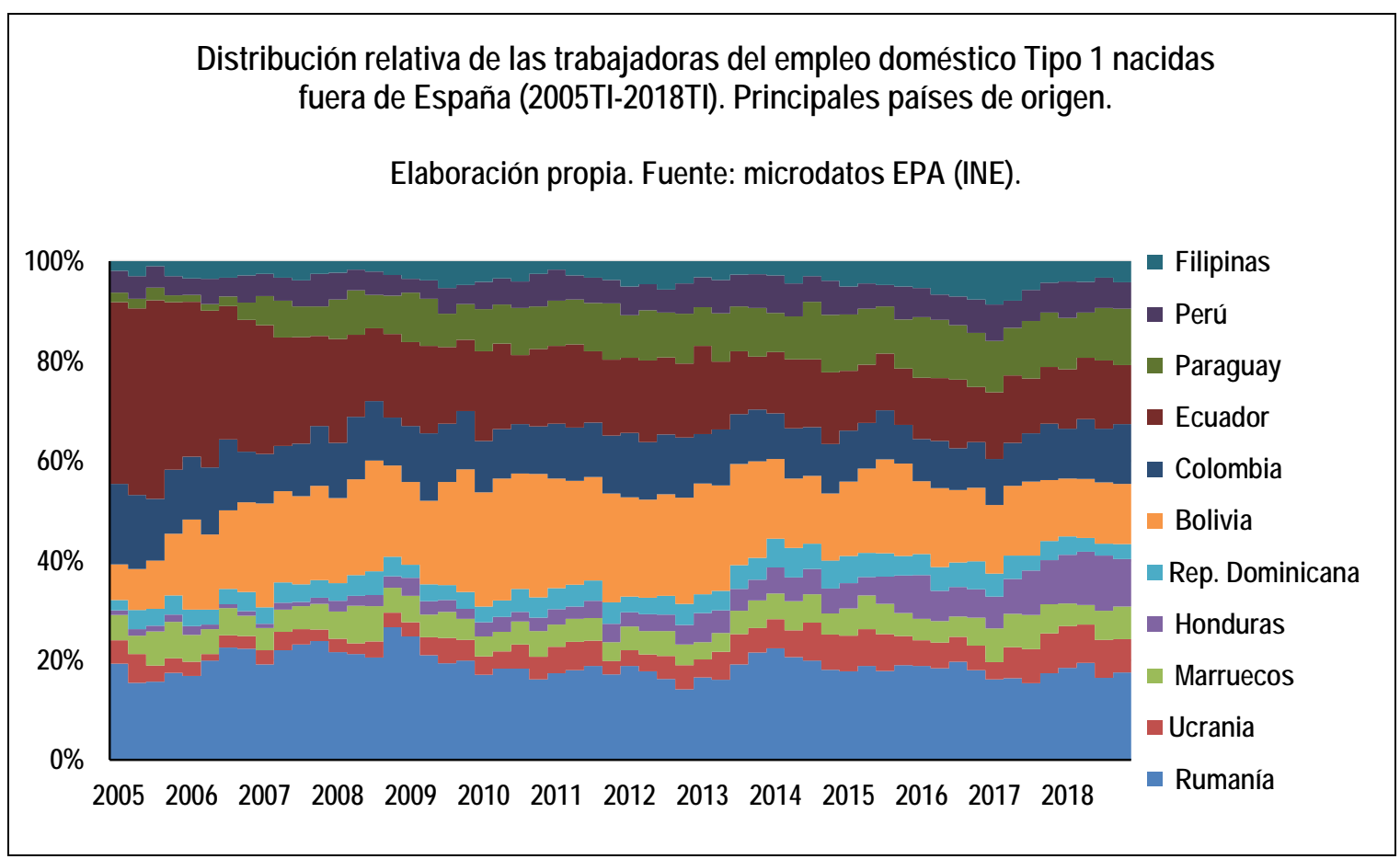




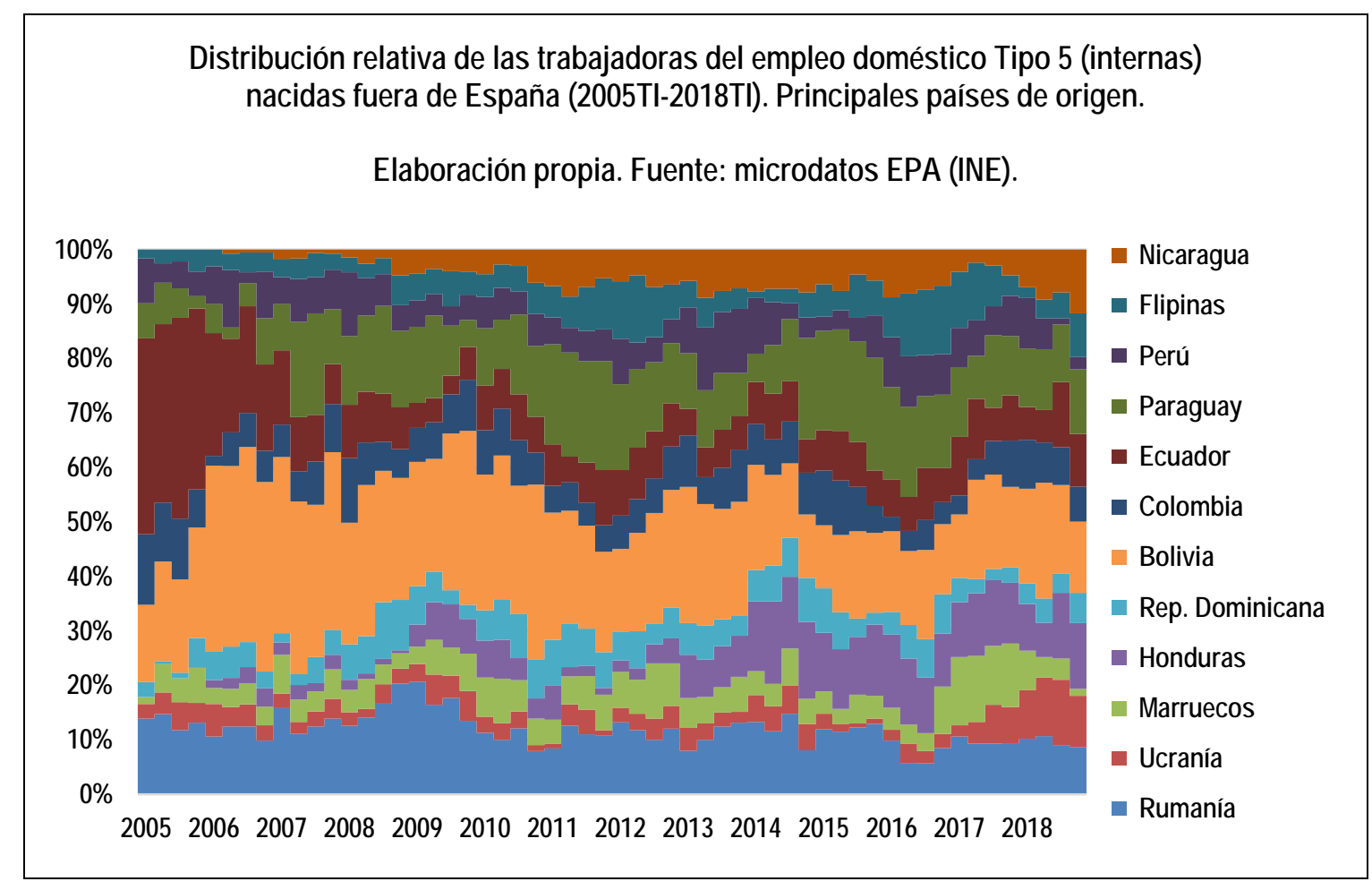

\subsubsection{Trabajadoras nacionales, extranjeras y el empleo doméstico ante la situación de su hogar.}

En este sentido, para corroborar si ha existido o no una sustitución de trabajadoras de origen extranjero por las de origen nacional o, sencillamente, tal y como ha ocurrido en otros sectores, la destrucción de empleo se ha cebado con trabajadores extranjeros en mayor proporción que los nacionales, los datos vienen a señalar que, en este caso, ambas dinámicas han confluido conjuntamente: por un lado, la presencia en el empleo doméstico de las nacionales españolas comenzó a caer al inicio de 2006, es decir, ya mucho antes del inicio de la recesión, y ello que el agregado, como se vio, no lo hizo hasta la segunda fase de la recesión; por el otro, sin embargo, desde el inicio de 2012 se produce un repunte claro de en torno a 50.000 trabajadoras nacionales que pasan a estar ocupadas en este sector mientras el empleo ocupado por nacionales extranjeras sigue cayendo hasta, al menos, la mitad de 2015. Así, la primera conclusión es que este tipo de empleo, el tradicional rechazado normalmente por los y las nacionales españolas como demuestra su temprana caída- dado su alto nivel de precariedad y sus muchas veces carácter ingrato en favor de las de origen extranjero tornó a convertirse en cierto refugio en durante la segunda fase de la recesión. Igualmente, la confluencia durante al menos dos años y medio de crecimiento del empleo doméstico ocupado por nacionales españolas con caída del que lo era por nacionales extranjeras lleva a plantearse como una hipótesis de gran verosimilitud que existieran no pocos casos de sustitución de las segundas en favor de las primeras por cambios, ahora, en las preferencias de los empleadores (lo cual, en cualquier caso, parecería denotar cierto desprecio hacia la 
trabajadora inmigrante ante la posibilidad de proporcionar a ésta y a la nacional similares regímenes laborales). De esta manera, no sería descabellado pensar que, cuando se adiciona el sector de actividad y la nota de nacionalidad, las trabajadoras inmigrantes se encuentren ante un doble tamiz de discriminación y depauperación de sus condiciones.

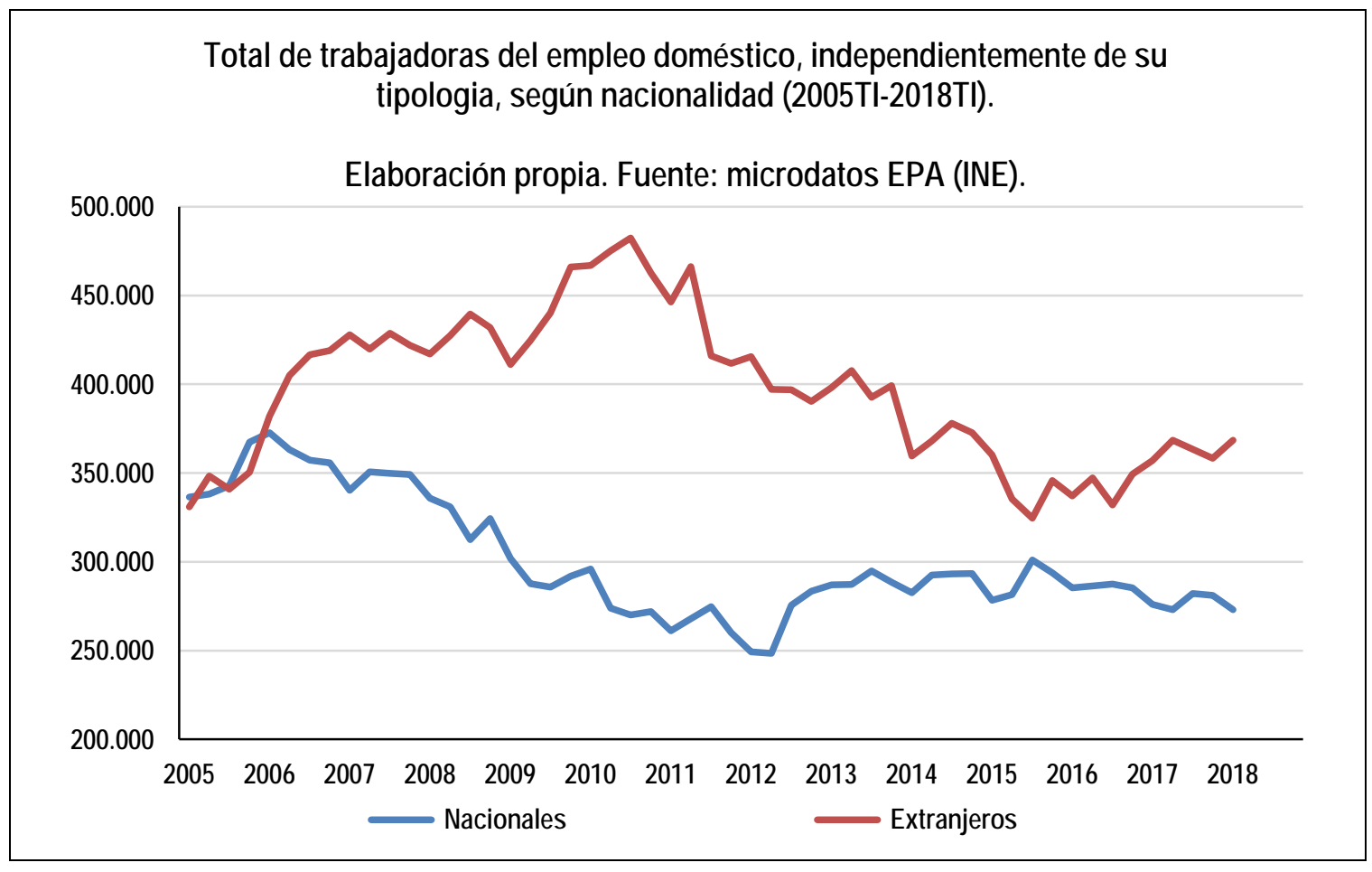

A su vez, un camino para indagar las causas sobre este cambio de preferencias de muchas nacionales españolas decidiéndose a entrar en el empleo doméstico tradicionalmente rechazado viene dado por la situación del hogar al que pertenecen. Y es que, el que ese incremento de la entrada de nacionales en el empleo doméstico coincida con la segunda fase de la recesión permite plantear la hipótesis de que el mismo actuara a modo de refugio -a pesar de entrar en declive precisamente en esa etapa- ante el agotamiento de las rentas del hogar de las empleadas o el recrudecimiento en su reducción dada la nueva recesión que aconteció desde finales de 2011. En ese sentido, hay dos datos que permiten verificar esta hipótesis: el primero, que es cuando el desempleo de las parejas conyugales de las trabajadoras nacionales alcanza el 20\%; el segundo, que la misma coincidencia se da con el hecho de que entre el desempleo de sus cónyuges, precisamente a partir de esta etapa, los estratos que mayor peso empezaron a tener drásticamente fueron los referidos al desempleo de larga y muy larga duración. En definitiva, todo ello apunta a un cambio en la presdisposición al empleo doméstico por parte de las trabajadoras nacionales ante un empeoramiento progresivamente más dramático de la situación socioeconómica de sus hogares. 

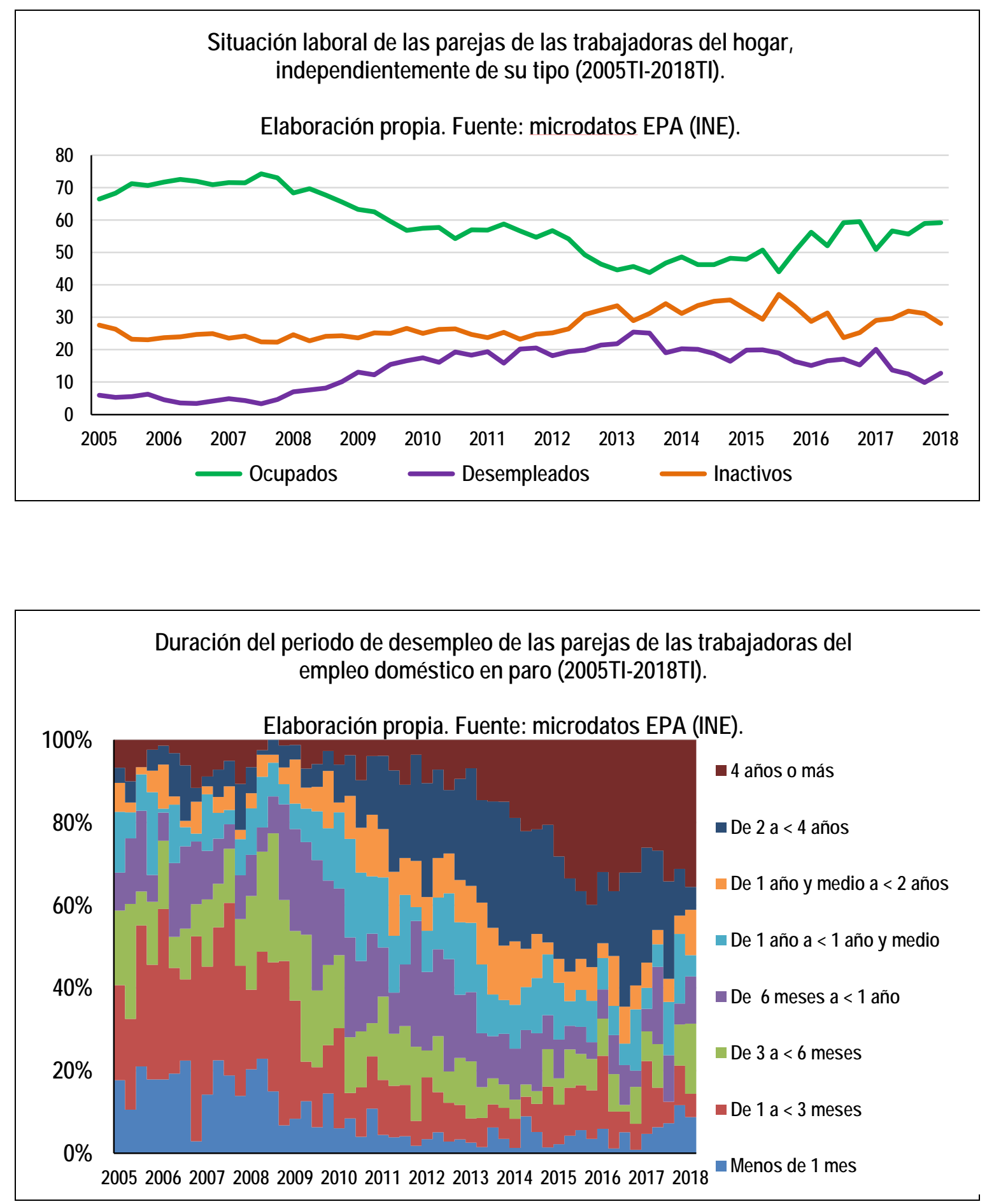

\subsection{Formación (y nacionalidad).}

Otro aspecto relevante de las características personales de esta sección de actividad lo constituye el grado de formación que atesoran las empleadas en él. En este caso, se trabaja sólo en relación a las trabajadoras, pues la baja cantidad de hombres hacia no 
representativa esta perspectiva de análisis. En compensación, se analiza la formación tanto para las nacionales españolas como las extranjeras.

En este sentido, destaca enormemente el fuerte diferencial de capital humano que existe entre las trabajadoras nacionales y las no nacionales, pues, como puede apreciarse para las trabajadoras Tipo 1 (ordinarias) nacionales, el estrato dominante es de "enseñanza obligatoria” mientras que, por el contrario, para las de nacionalidad extranjera, hay un equilibrio entre éste y el de "bachillerato", es decir, el inmediatamente superior. Las conclusiones que se extraerían al respecto es el de que este tipo de ocupación es realizado, en el caso de las nacionales, por trabajadoras de baja formación mientras que, por el mero hecho de la extranjería, la mayor formación de las trabajadoras no nacionales se convierte en un factor no relevante en la comparación con la posibilidad de entrada en otro tipo de actividades para las que poseen mayor capital humano.

El mismo patrón se repite para el caso de las trabajadoras del Tipo 5 o internas. Para este segmento, la baja presencia de españolas, al arrojar resultados completamente dispares entre trimestres consecutivos tal y como ha ocurrido ya en muchas variables en relación a los varones, de modo que se ha procedido a utilizar una medición agregada y posterior promedio para el conjunto del periodo que se analiza.

Se evidencia así una plasmación más de convenciones sociales ciertamente denigrantes -y probablemente discriminatorios- para las trabajadoras inmigrantes, cuyo capital humano les permitiría acceder, al menos tras un tiempo de adaptación, a trabajados de mayor valor añadido y remuneración, pero a las que, sin embargo, el mercado laboral ubica en sectores fuertemente precarios a plena disposición de los empresarios / cabeza de familia. 

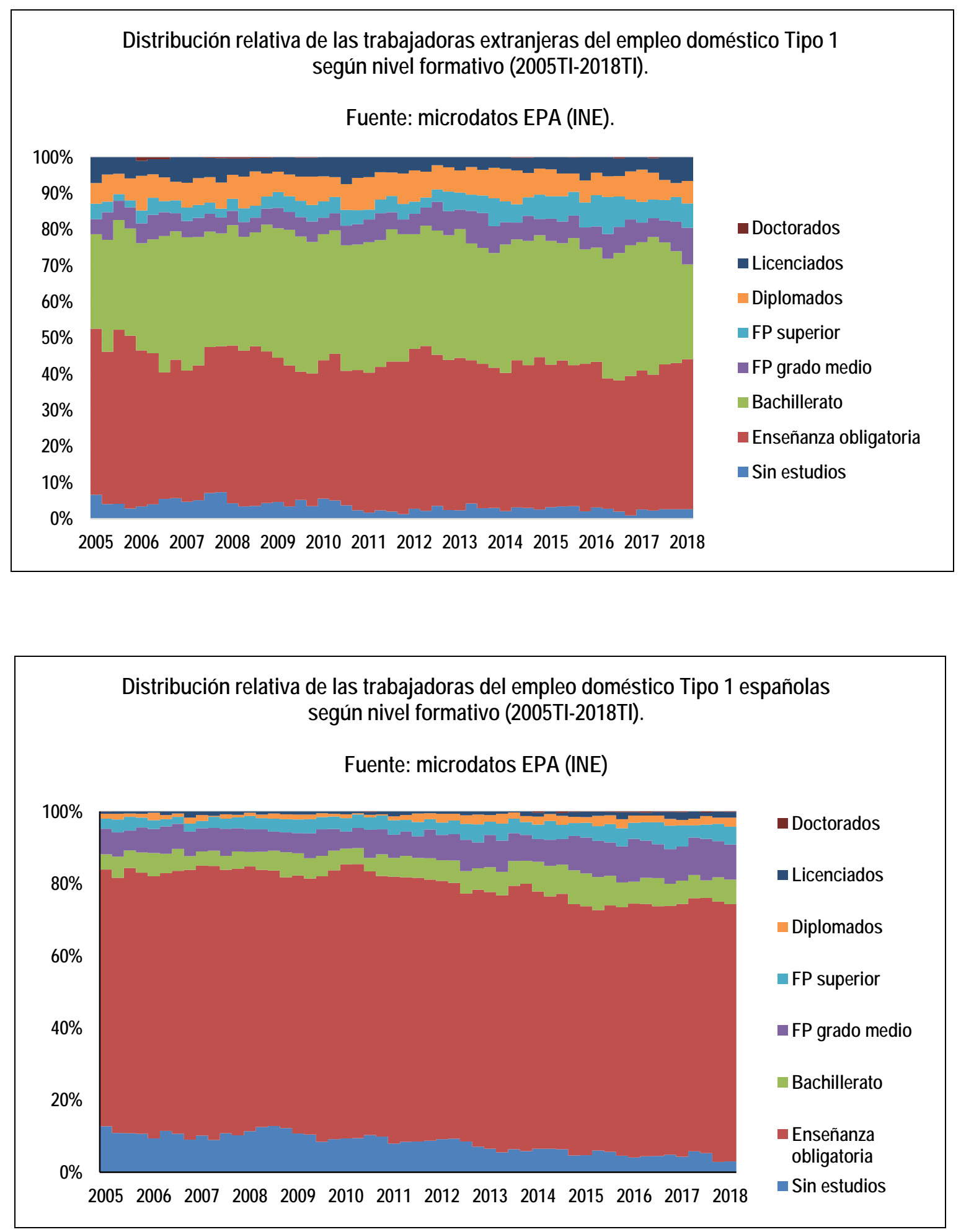


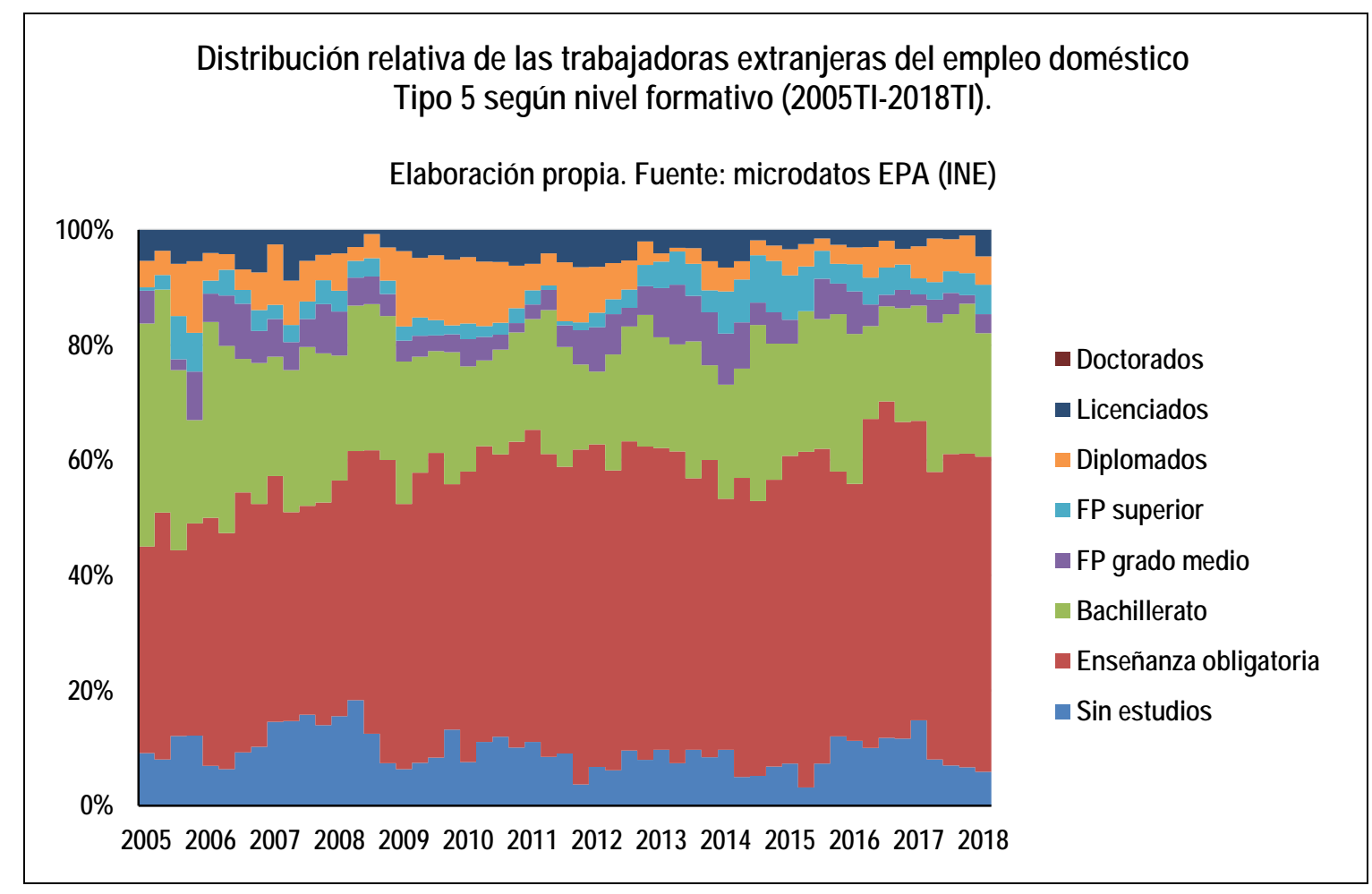

Distribución las trabajadoras nacionales en el empleo doméstico Tipo 5 según el agregado de todos los puestos existentes en el total del periodo (2005TI-2018TI). Elaboración propia. Fuente: microdatos EPA.

\begin{tabular}{|c|c|}
\multicolumn{1}{c|}{} & $\begin{array}{c}\text { Promedio 2005TI- } \\
\text { 2018TI }\end{array}$ \\
\hline Sin estudios & 15,99 \\
\hline $\begin{array}{c}\text { Enseñanza } \\
\text { obligatoria }\end{array}$ & 60,22 \\
\hline Bachillerato & 7,43 \\
\hline $\begin{array}{c}\text { FP grado } \\
\text { medio }\end{array}$ & 6,50 \\
\hline FP superior & 2,03 \\
\hline Diplomados & 7,09 \\
\hline Licenciados & 0,74 \\
\hline
\end{tabular}

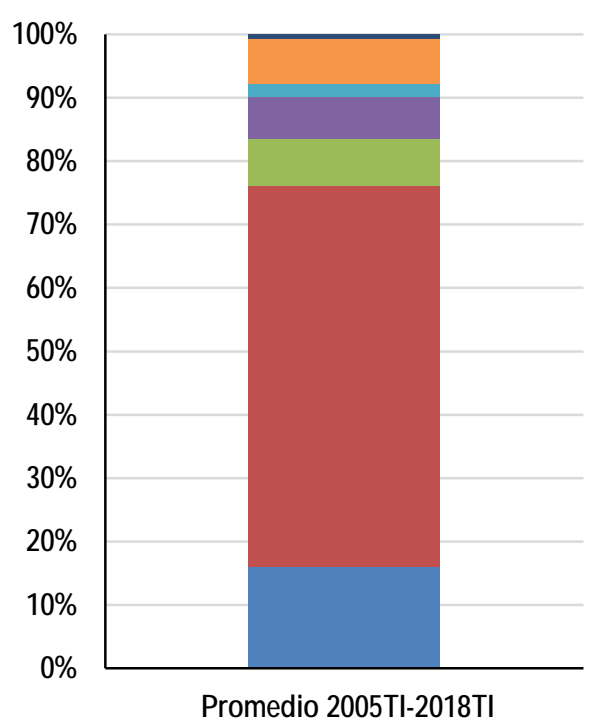




\section{RÉGIMEN JURÍDICO-LABORAL.}

\subsection{Temporalidad y antigüedad.}

Como normalmente es habitual en los estudios sobre el mercado de trabajo español, la principal variable de estudio en el ámbito del régimen jurídico-laboral es la de la temporalidad, factor dramáticamente diferencial de nuestro mercado laboral respecto de los de su entorno junto a la elevada tasa de para y, además, en mutua interrelación.

Así, en materia de temporalidad, el principal contingente de empleo, es decir, las mujeres del Tipo 1, poseían de manera secular una tasa sustancialmente superior a la agregada (más 20 puntos superior en el inicio de 2007) que, sin embargo, terminó por confluir con ésta entre finales de 2015 y el inicio de 2016. El caso contrario se da para las trabajadoras del Tipo 5, las cuales, progresivamente, han ido alejándose de la tasa general en el sentido un peso cada vez mayor del empleo indefinido. En otras palabras, aquel tipo de trabajadoras que en mayor medida conservaron su empleo, como viene siendo habitual en el mercado laboral español, habrían sido las que ya poseían un vínculo más estable con las familias con las que mantenían relación. En el caso de los hombres (los del Tipo 1, pues los del Tipo 5 son tan exiguos que no existe muestra representativa), su temporalidad ha oscilado, aunque con importantes estribaciones, en torno a la tasa promedio del mercado de trabajo.

Un dato relevante en este sentido es el cambio en la distribución relativo entre tipos de contrato temporal que se da a partir de los cambios regulatorios en materia de Seguridad Social en 2012. Y es que, aunque en un sector tan informal y desprovisto de control, la frontera entre la categoría "verbal” y la de “otro tipo" (que con gran probabilidad responda, directamente, a no disponer de contrato) pueda ser muy delgada, sin embargo, coincidiendo con la referida reforma de 2012 en materia de Seguridad Social, se produce un incremento claro de los "verbales" en detrimento de los de "otro tipo”. Intentando dar una explicación a esta cuestión es probable que el aumento ya visto en materia de afiliación y regularidad a partir de ese año se vehiculara a través de este tipo de formas contractuales a pesar de la dificultad de prueba de la misma, pues para la obligaciones de afiliación y alta es suficiente esta forma verbal en la constitución del contrato. 

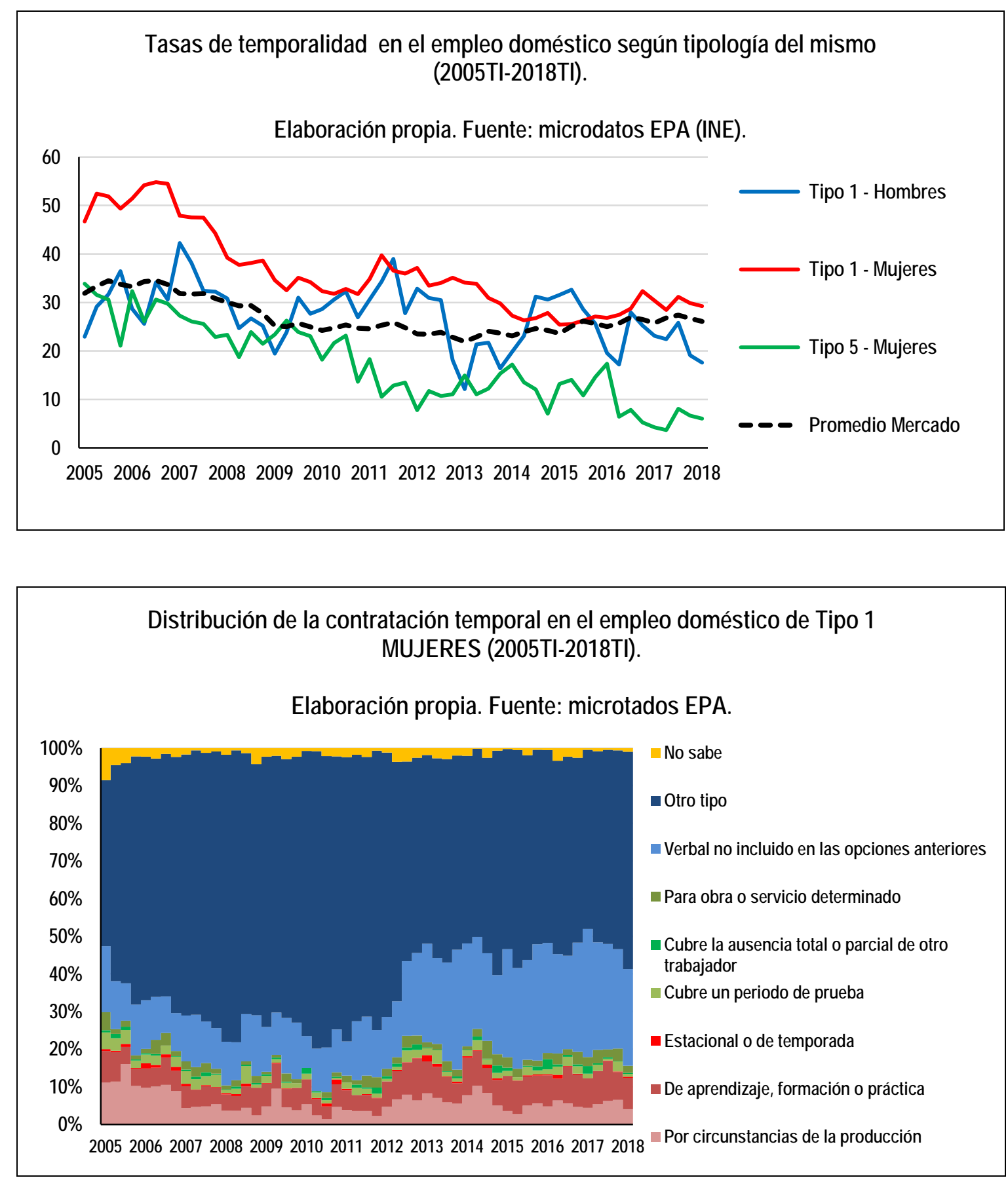

Continuando, cabe señalar que, hasta 2014, este continente principal "Mujeres - Tipo 1”, disponía de contratos en meses muy por debajo de la media del mercado de trabajo. Así, no es hasta la etapa de asemejamiento entre tasas de temporalidad cuando este colectivo homogeniza también la duración de sus contratos temporales con el promedio del mercado. De este modo, las trabajadoras Tipo 1 que mantuvieron su empleo temporal o fueron contratadas temporalmente pasaron a disponer de relaciones contractuales más sustancialmente más elevadas, y crecientes, que en la etapa previa. En cuanto a los contratos temporales inferiores a un mes, en el caso de las mujeres del Tipo 
1, éstas, como dato positivo, han mantenido un leve diferencial superior (mayor duración) respecto del promedio del mercado laboral, mientras que, en el caso de los hombres y para ese mismo subgrupo, la duración ha sido sustancialmente menor, hecho que, con gran probabilidad, tiene su causa en las diferencias ocupacionales por sexo existentes dentro de este sector de actividad (y que más adelante se mostrarán).
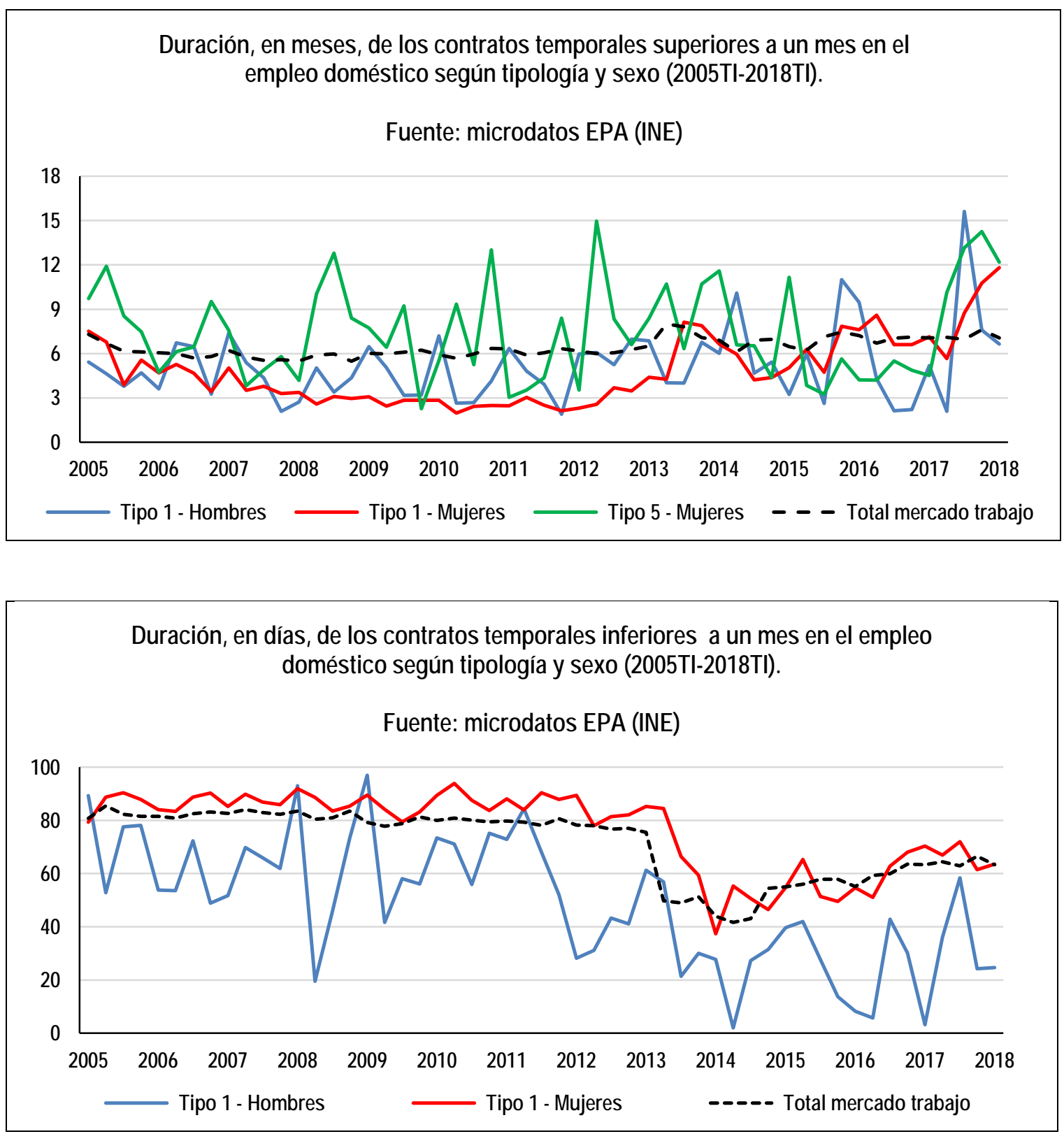

Consecuentemente a todo lo anterior, especialmente lo referido a las tasas de temporalidad, los niveles de rotación que estas generan han tenido como consecuencia que la antigüedad ganada en el empleo doméstico sea muy inferior al promedio del mercado laboral. Y ello aunque, fruto de la caída en las tasas de temporalidad, 
lógicamente dicha antigüedad acumulada vaya en aumento. No obstante, la correlación grado de temporalidad - nivel de antigüedad no es total, pues, aunque es cierto que los hombres Tipo 1 sufrían una tasa similar a la del mercado de trabajo, su nivel de antigüedad es el más elevado; a la inversa, las mujeres internas (Tipo 5), cuya tasa de temporalidad era la menor y, además, se había reducido a niveles marginales, disponen de la menor antigüedad. Por exclusión, estas aparentes contradicciones podrían estar causadas por una reducción del tiempo de duración de las trabajadoras con contrato indefinido, los cuales, aunque crecientemente mayoritarios, estarían entonces viendo precarizadas sus condiciones laborales cuanto menos en términos de tiempo de trabajo.

Puntualizando todo lo anterior, estas dinámicas son especialmente paradójicas en el caso de las trabajadoras internas, ya que con las mismas puede llegar a terminar por trabarse cierta relación afectiva-emocional (algo que estaría fuertemente vinculado a su reducción en la tasa de temporalidad).

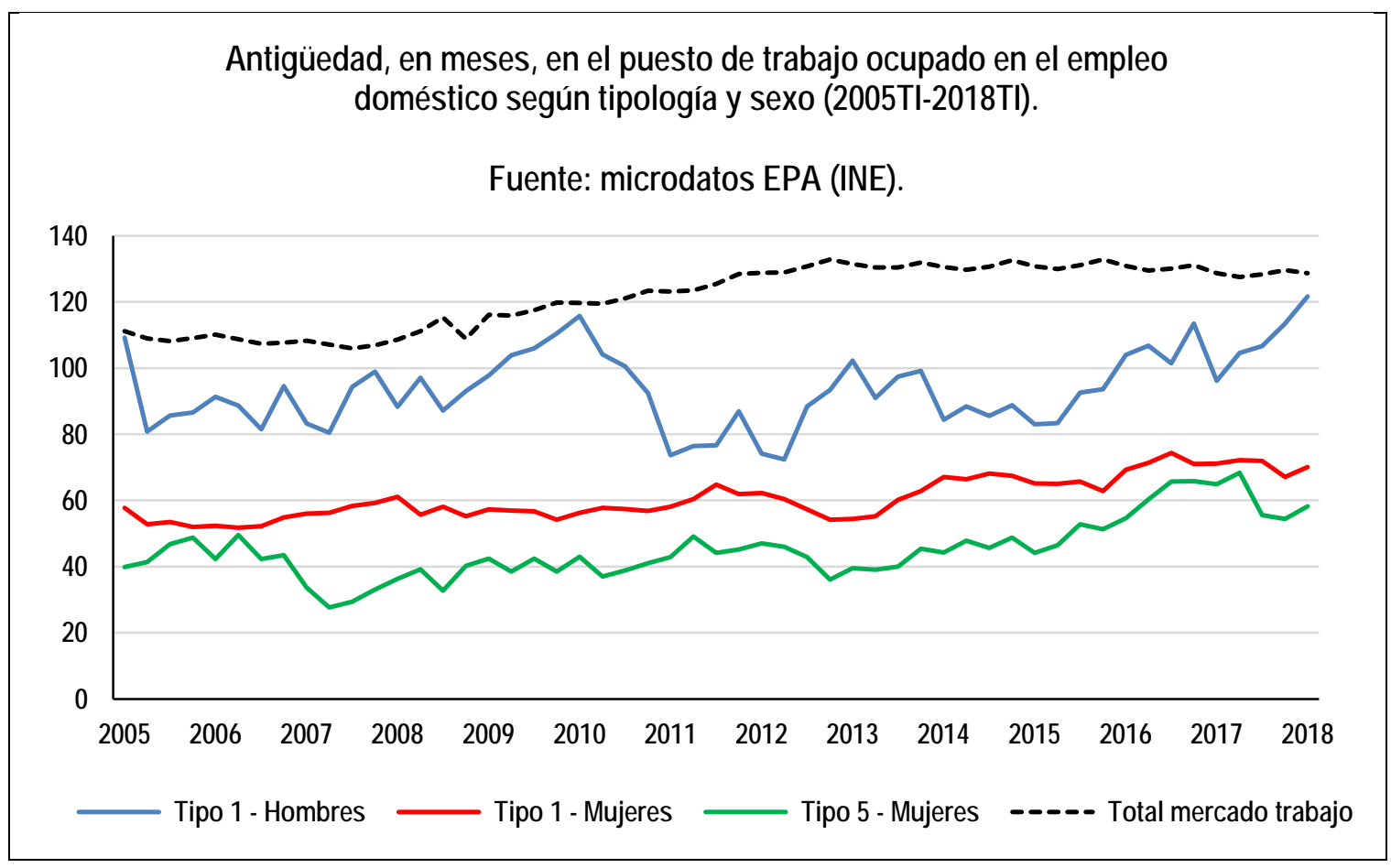

\subsection{Parcialidad, jornada semanal efectiva y absentismo por siniestralidad.}

En materia de tiempo de trabajo, la primera variable de relevancia para el análisis, lógicamente, radica en la evolución de la parcialidad. En este sentido, el empleo doméstico se caracteriza porque las mujeres Tipo 1 poseen, de manera endémica, un diferencial desproporcionado respecto de la tasa promedio del mercado, pues la de las mismas se encuentra secularmente en niveles en torno a 50 puntos por encima de dicho promedio. En el caso de los hombres dentro ese mismo subgrupo, su tendencia se movía en torno al promedio agregado hasta el inicio de 2010, momento a partir del cual, salvo 
algunas excepciones trimestrales ha mantenido un diferencial de entre 7 y 15 puntos diferenciales.

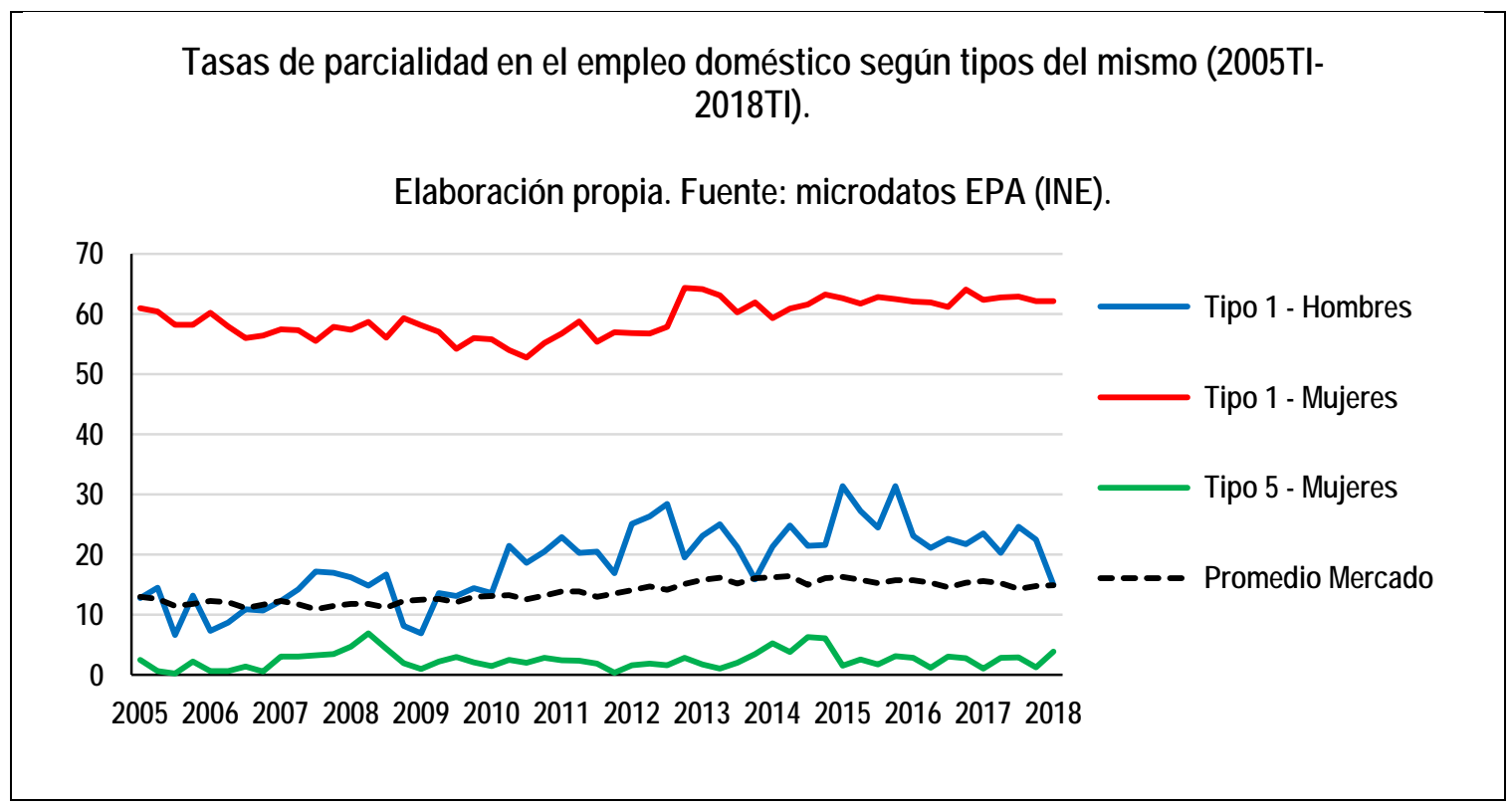

En cuanto a la involuntariedad en la parcialidad, el empleo doméstico se caracteriza por niveles considerablemente superiores a los ya de por sí elevados de que, en perspectiva comparada, adolece el mercado laboral español. De hecho, el tradicional rechazo de los trabajadores varones a este sector de empleo, a pesar de realizar ocupaciones diferentes en su seno, se ve incrementado en lo que a que el mismo no sea a jornada completa se refiere, pues la mayor parte de los trimestres desde 2010 el nivel de involuntariedad -poseer un contrato parcial siendo la causa primera de ello el no poder haber accedido a uno a tiempo completo- supera el 80\%, llegando en numerosas ocasiones a valores superiores al 90\%. En el caso de las mujeres, llegó a situarse en 20 puntos superior al promedio nacional entre 2010 y 2015, oscilando el resto de trimestres en un diferencial de entre 10 y 15 puntos. 


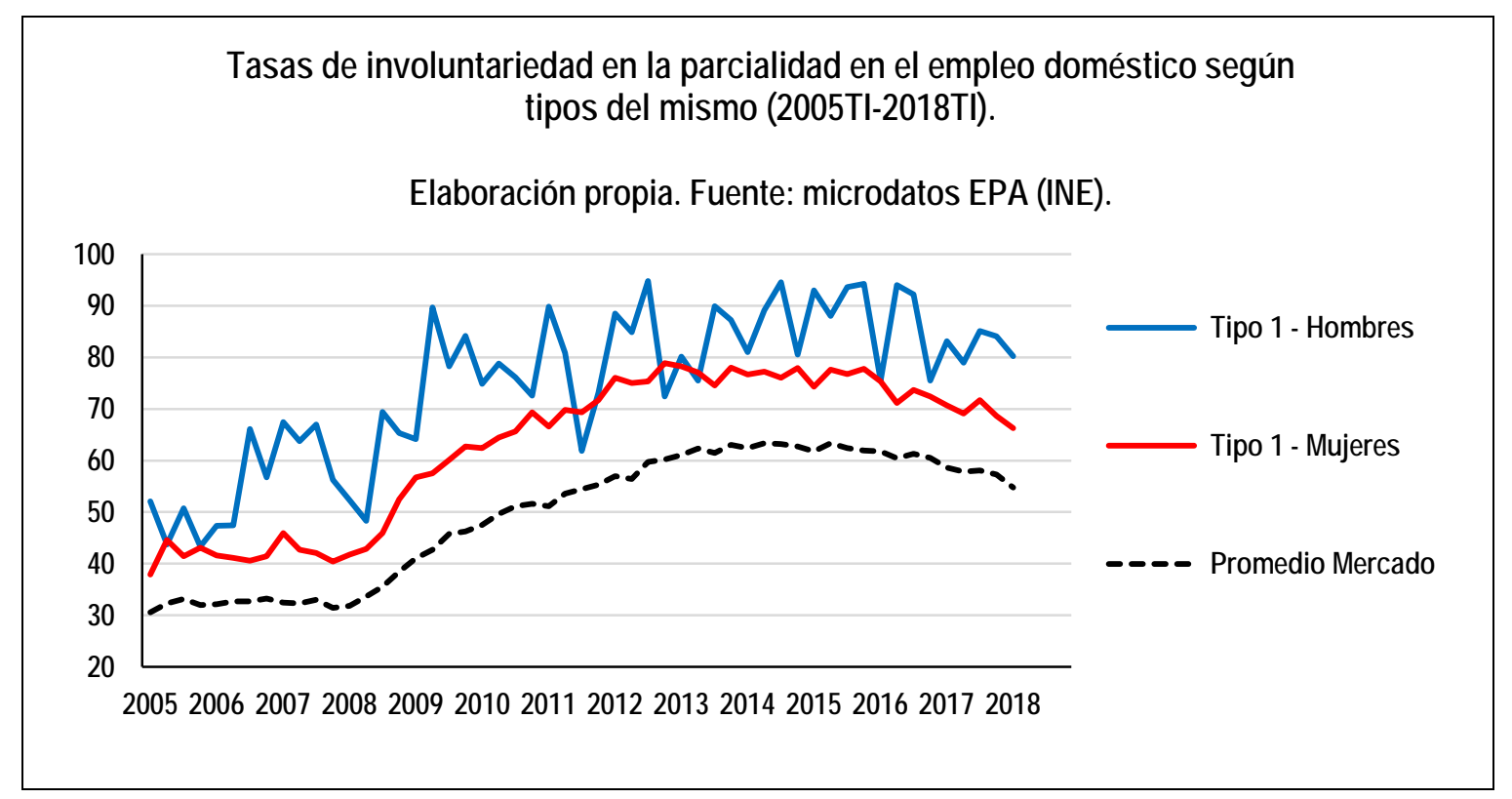

En cuanto a las causas que determinan que el resto de trabajadores parciales no sean involuntarias, destaca que éstas son drásticamente diferentes según sexos: en el caso de los hombres, aumentar su capital humano (y ello a pesar de las fuertes irregularidades mostradas en el gráfico correspondiente dado el bajo número de los mismos), mientras que, en el caso de los mujeres, esa "voluntariedad" proviene de la asunción de cargas familiares.

\subsection{Régimen laboral y nacionalidad.}

Aunque el estudio realizado hasta aquí analiza de manera profusa el conjunto del régimen jurídico laboral y los condicionantes personales en el empleo doméstico, el hecho de que se haya tratado durante las dos últimas décadas de un empleo que, además de feminizada, estaba fuertemente integrado por trabajadoras extranjeras, como ya tuvo ocasión de exponerse detenidamente, dota de gran interés hacer aquí una breve mención a cómo se han comportado estas variables del tipo jurídico-laboral en función de la nacionalidad.

Así, comenzando por el binomio temporalidad - antigüedad, tradicionalmente las trabajadoras extranjeras, en este sector ya de por sí extraordinariamente precario, adolecían de una tasa de temporalidad mayor que, sin embargo, ha acabado por confluir, manteniéndose estable alrededor del 25\%-30\%, con la de las nacionales españolas. Sin embargo, a la inversa, los niveles de antigüedad -crecientes en ambos casos dada la menor temporalidad- son mucho más elevados en el caso de las trabajadoras nacionales (si bien ha decrecido en los últimos años). Lógicamente, ello sólo puede explicarse por la menor duración ya sea de los contratos temporales o indefinidos por los que se rigen las trabajadoras de nacionalidad extranjera. 

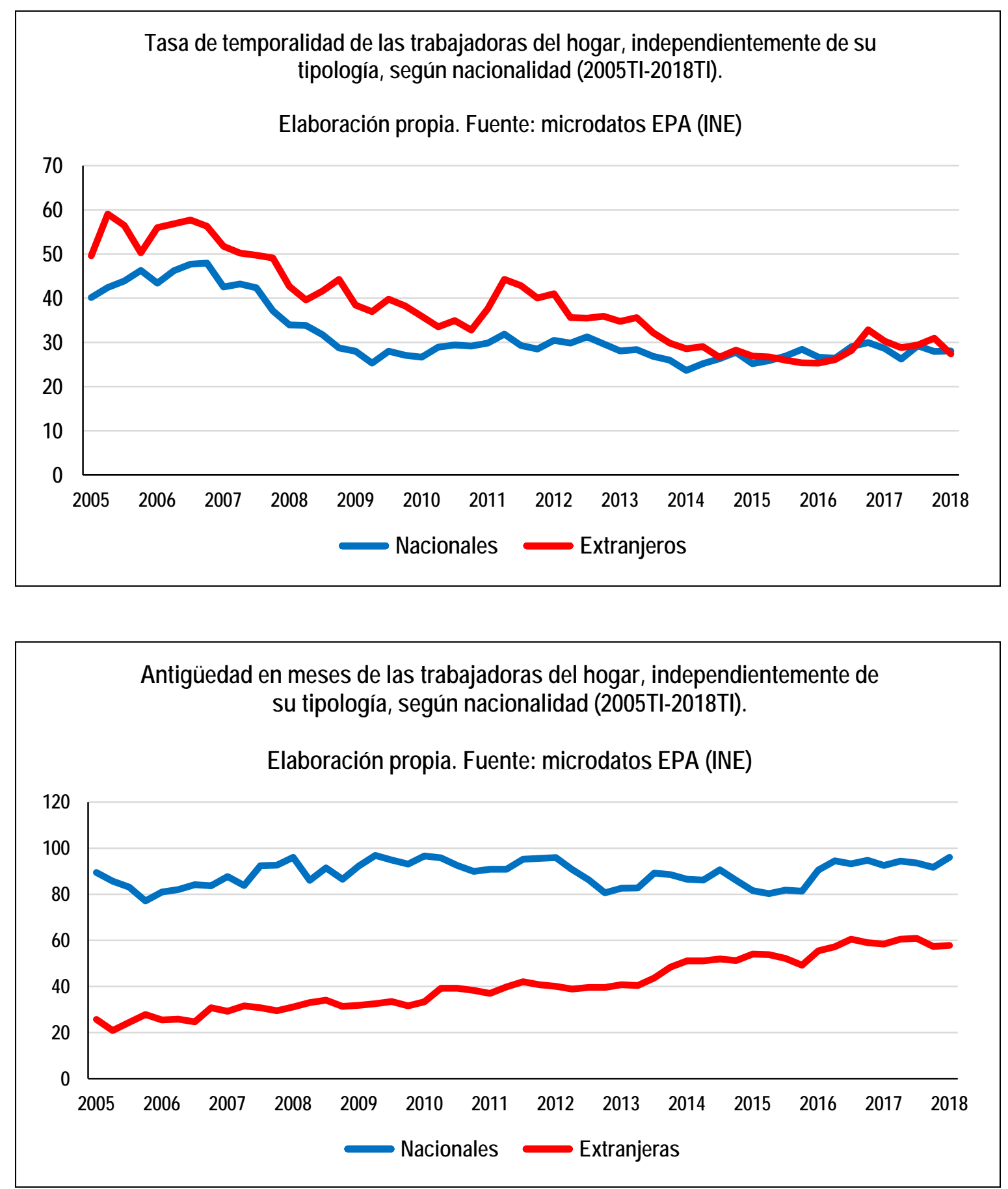

Continuando, algunas de las dinámicas más interesantes concurren en el caso de la parcialidad. Y es que, por un lado, como era predecible, la tasa de parcialidad de las extranjeras ha sido constantemente superior a la de las nacionales, si bien mostrando, y de ahí la relevancia, una práctica total independencia del ciclo económico en valores de entre el 60\% y el 70\%; por el otro, a la inversa, en el caso de las españolas, es esa entrada en sector a modo, principalmente, de refugio compensatorio de rentas en el hogar, tal inserción se produce esencialmente mediante fórmulas a tiempo parcial, pues 
la tasa de parcialidad de las mismas escaló casi 20 puntos entre mediados de 2011 y el comienzo de 2013. Por otro lado, en cuanto a la involuntariedad, de nuevo es mayor en el caso de las trabajadoras no nacionales.
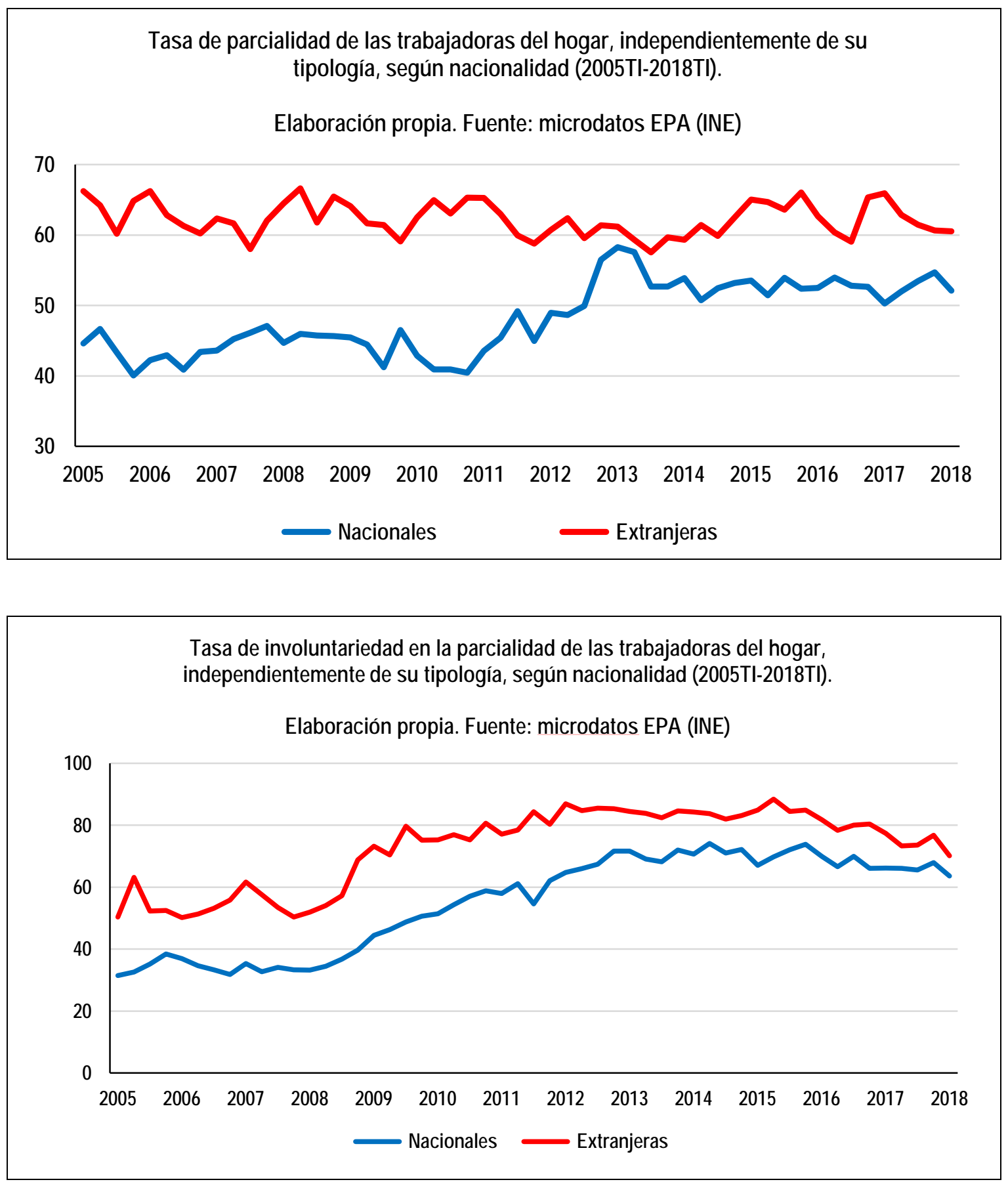
Uno de los elementos más relevantes desde esta perspectiva es la evolución de la jornada efectivamente realizada a lo largo de la semana, plano desde el que pueden hacerse varias apreciaciones: en primer lugar, a pesar de su nivel de parcialidad algo superior a la media, la jornada efectiva masculina (Tipo 1), ha discurrido en valores cercanos al promedio del mercado de trabajo, lo que vendría a indicar que los trabajadores a tiempo completo de este tipo trabajarían algo más que dicho promedio; en cuanto a las trabajadoras Tipo 1, su jornada se ha mantenido esencialmente estable, siendo el caso de las internas donde mayor reducción se aprecia de la jornada, especialmente a partir de mediados de 2014.

Profundizando en ello, este último dato es especialmente positivo, pues si se desagrega el segmento de las trabajadoras internas por estratos de jornada efectiva semanal, a partir de mediados de 2014, las jornadas que se movían (en horas efectivas semanales) en las horquillas 41-50, 51-60, 61-70, 71-80, 81-90 y más de 90 . Y es que, estos estratos han pasado se abarcar al 50\% las trabajadoras internas al inicio de la serie, encubriendo por tanto numerosos casos de abuso en lo relativo a jornadas máximas, a en torno al 20\% en 2018.

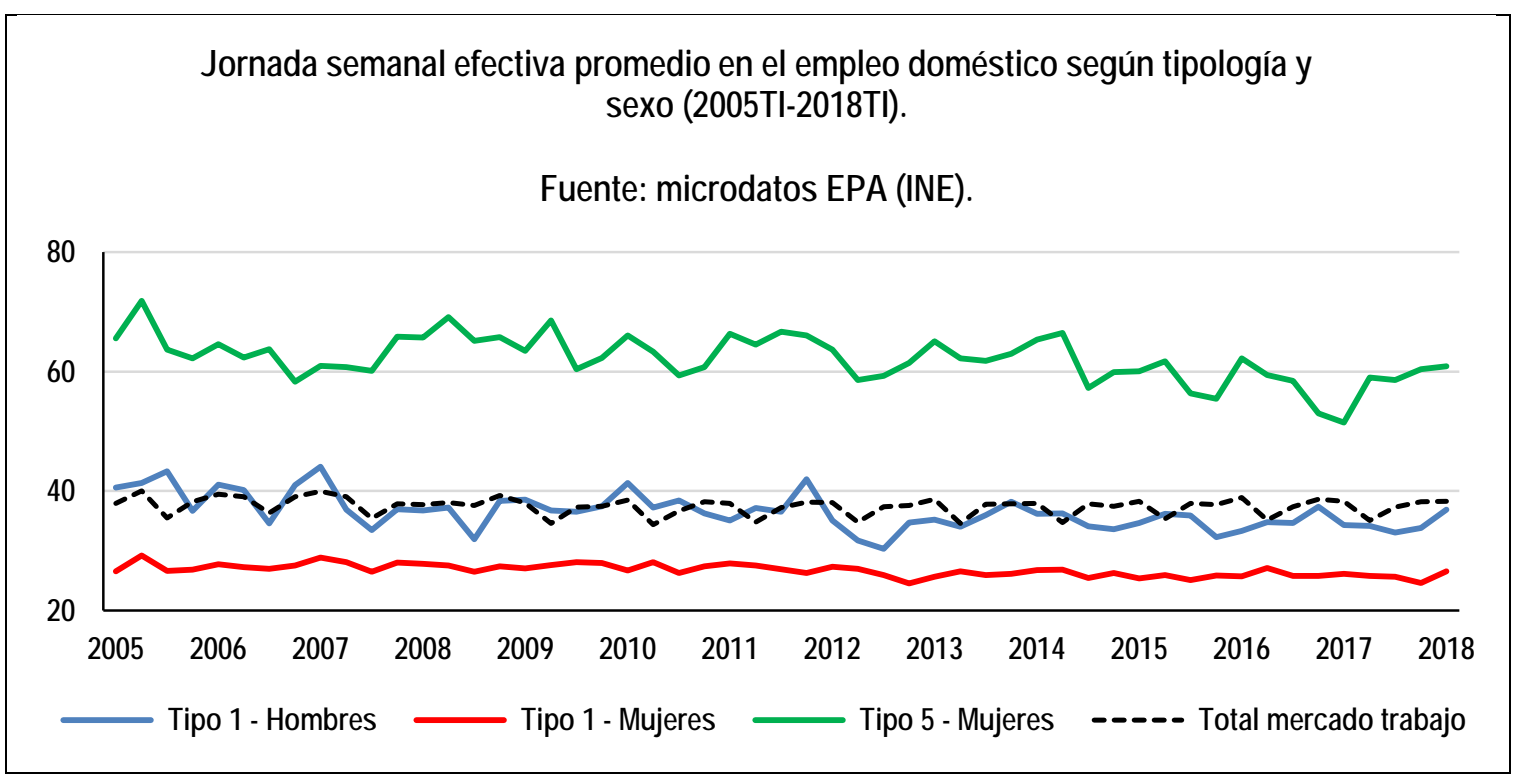




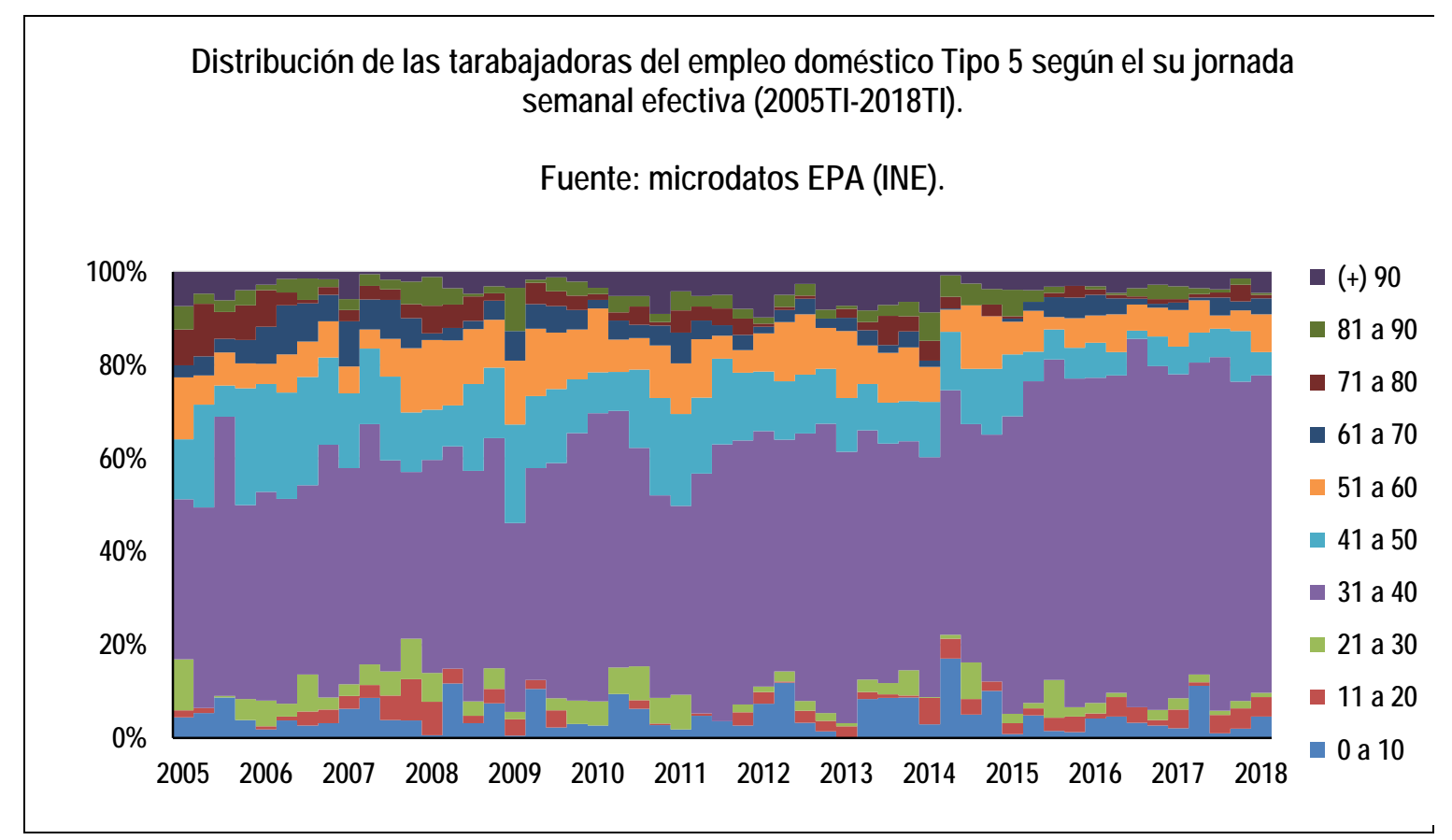

Finalmente, en lo relativo al absentismo, aunque puede haber una multiplicidad de causas, el carácter extraordinariamente precario de estos puestos de trabajo unido a la altísima oferta de trabajadoras para ocuparlos, es decir, la alta sustituibilidad de las ocupadas provoca que las mismas, incluso en situación de enfermedad, hayan de acudir a su puesto de trabajo. En consecuencia, hay un fuerte diferencial a la baja en el absentismo de las trabajadoras del empleo doméstico respecto del total, llegando a ser prácticamente insignificante en muchos momentos.

Incidiendo en esta cuestión, si se evalúa el prototipo de trabajadores o trabajadores del sector que inciden en el absentismo, destacan dos cuestiones: en primer lugar, que hasta 2012, coincidiendo con el cambio normativo en materia de Seguridad Social, se registran los primeros casos de absentismo por enfermedad en el caso de las internas, lo que indica el grado de precariedad y abuso que, en muchas circunstancias, podían estar ejecutando su labor en tanto, para el caso concreto de este tipo de trabajadoras, es frecuente la realización de labores como el levantamiento de cargas y similares; en segundo lugar, que el absentismo en el caso de los hombres tiene un peso sobre el total del mismos, en la mayoría de los trimestres, superior al peso de los trabajadores masculinos en este sector de actividad, es decir, que su propensión al absentismo por enfermedad -dentro de los niveles marginales en los que, no obstante, se mueve este sector- es mayor que en el caso de las mujeres o, si se prefiere, que ello es indicativo de un menor riesgo en la pérdida del empleo. 

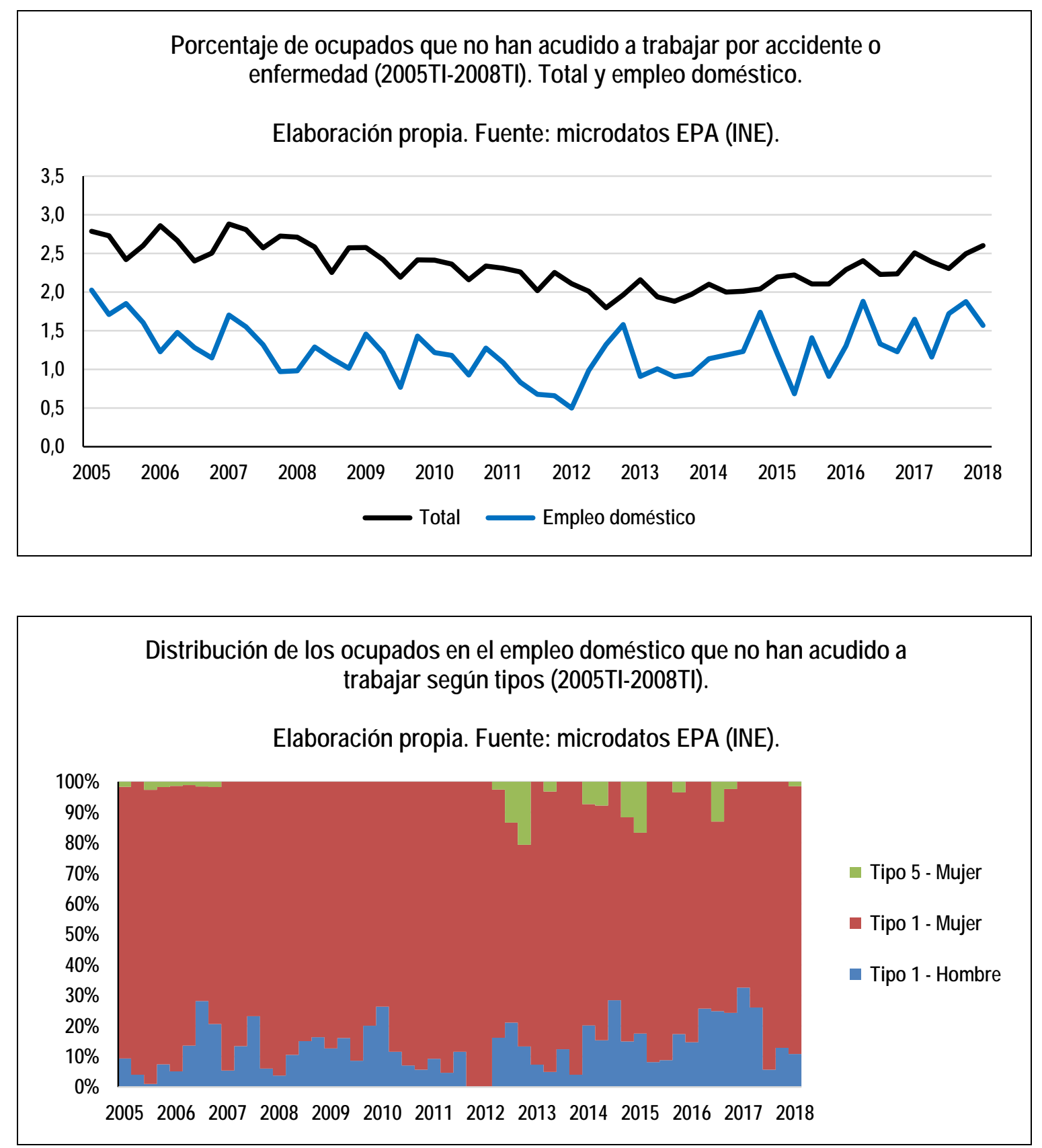

\subsection{Distribución ocupacional.}

Entrando en el último punto del estudio, cabe realizar el interesante ejercicio de analizar la sección de actividad referida al empleo doméstico desde la perspectiva las diferentes ocupaciones que puedan darse en su seno, es decir, cruzar, en un sentido técnico, la información aportada por la Clasificación Nacional de Actividades Económicas (CNAE09, en su división 97, como ya se sabe) con la de la Clasificación Nacional de Ocupaciones (CNO). No obstante, ha de tenerse en cuenta que, en este caso, es más complicado establecer correlaciones perfectas entre la CNO94 y la de 
CNO11 como, al menos a estos efectos, sí lo ha sido en relación a la CNAE, de modo que las series aparecerán divididas en dos: hasta el cuarto trimestre de 2010 y a partir de dicho trimestre.

En este sentido, la primera cuestión que cabe resaltar es que, lógicamente, dado el carácter omnicomprensivo de la categoría generalista de "empleados de hogar" (CNO94) o “empleados domésticos” (CNO-11), ésta posea el peso mayoritario tanto para las trabajadoras de Tipo 1 como para las de Tipo 5 (internas). De este modo, hemos de entender el resto de categorías ocupacionales, ya que la información que se aporta lo es en relación a la ocupación principal, como supuestos en los que los trabajadores encuestados realizan esa específica tarea correspondiente, siendo el resto secundarias y, por tanto, desgajándose, a modo de subcategoría funcional, de la categoría genérica antes apuntada. En cualquier caso, ello no deja de plantear problemas, tal y como ocurre con la ocupación referida a los exclusivos trabajos de limpieza, cuyo seguimiento se hace imposible, para este caso concreto, entre ambas CNO. Dicho esto, destacan varias dinámicas, siendo la principal el peso creciente que para las trabajadoras internas ha ido adquiriendo el que su tarea principal sean los cuidados personales, como por ejemplo la dependencia, pasando de suponer el 5\% del total en 2005 hasta valores de en torno al $20 \%$ en 2018. Igualmente, cómo, gracias al cambio de CNO a partir de 2011, se ha podido aislar que alrededor del 8\% de las trabajadoras del Tipo 1 tienen como tarea central el cuidado de niños. 


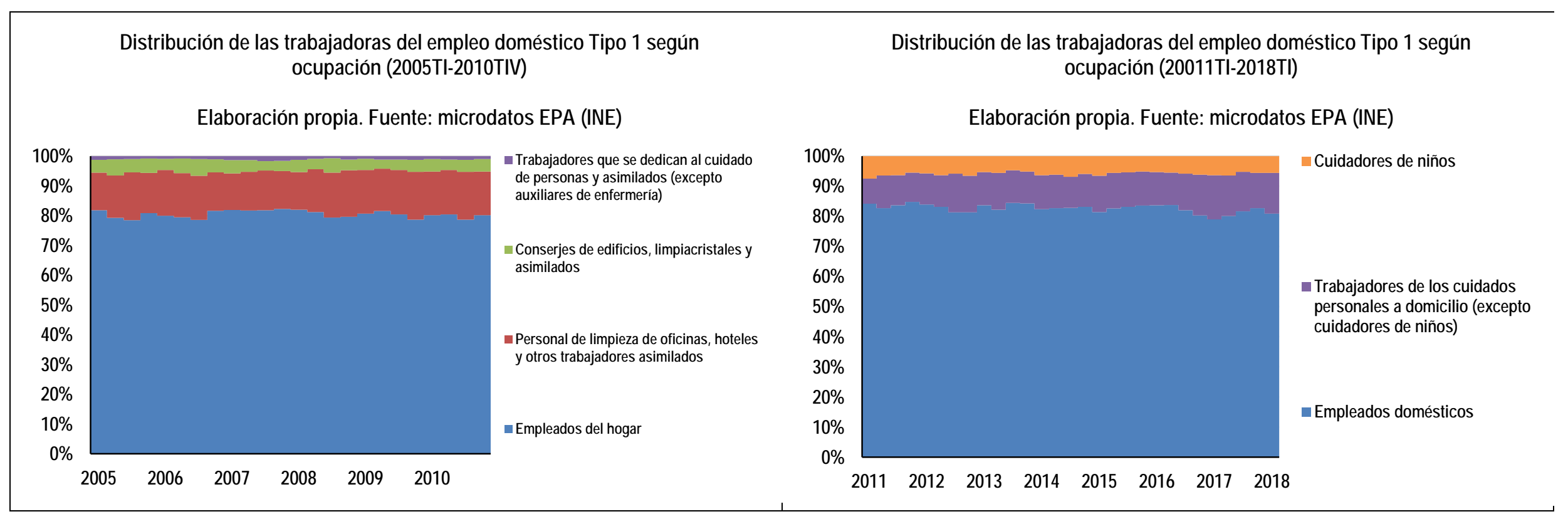




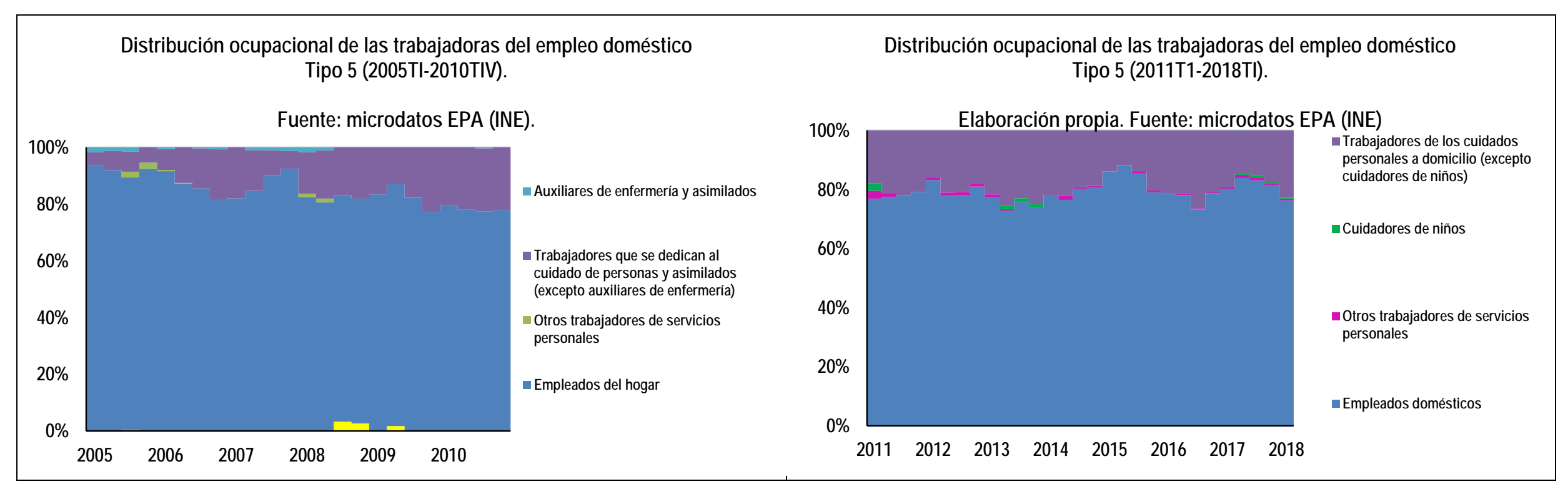


Desde esta perspectiva, destaca drásticamente que la categoría genérica de empleo doméstico o del hogar, según la CON de que se trate, tiene un peso no sólo muy inferior al caso de las mujeres, sino marginal en según qué etapas y tipos de empleados, tal y como ocurre con los de Tipo 1 en el periodo de la CON-94 (4,72\%) y que, si bien es algo superior en el de la CNO-11 (12,98\%), posee un diferencial de en torno a 70 puntos respecto a las mujeres. Así, por el contrario, los varones parecen estar mucho más especializados, alejados de esa supracategoría que, de facto, con casi toda seguridad engloba a las demás. Así, los varones de esta rama de actividad se encuentran considerablemente especializados en tareas concretas (o, si se prefiere, mucho menos ubicados en la realización del global de tareas). De este modo, destacan las labores de jardinería o conducción privada.

A su vez, cabe señalar que este punto final del análisis lleva a replantearse si la presencia de varones el empleo doméstico es fielmente la que se reflejaba al inicio del estudio, y ello por el importante peso de ocupaciones relacionadas, esencialmente, con la construcción y reforma de viviendas según la CNO. Y es que, analizados estos datos, cabe la posibilidad de que numerosos varones que, entonces, deberían ubicarse en las divisiones de la CNAE correspondientes igualmente a la construcción y afines, cuando realizan sus funciones contratados directamente por hogares, se incluyan en la división 97 de la misma, reduciendo su grado de feminización pero sólo desde el punto de vista estadístico, ya que no se trataría de empleados domésticos como tal, sino obreros y peones de otras divisiones de actividad.

\section{Distribución relativa de las principales ocupaciones realizadas por los trabajadores varones en el empleo doméstico Tipo 1. Promedio del periodo 2005TI-2018TI. Elaboración propia. Fuente: microdatos EPA (INE).}

\begin{tabular}{|l|c|}
\hline \multicolumn{2}{|c|}{ 2005TI-2010TIV } \\
\hline $\begin{array}{l}\text { Vigilantes, guardianes y } \\
\text { asimilados }\end{array}$ & 61,98 \\
\hline $\begin{array}{l}\text { Conserjes de edificios, } \\
\text { limpiacristales y asimilados }\end{array}$ & 17,04 \\
\hline $\begin{array}{l}\text { Personal de limpieza de oficinas, } \\
\text { hoteles y otros trabajadores } \\
\text { asimilados }\end{array}$ & 8,43 \\
\hline Empleados del hogar & 4,72 \\
\hline $\begin{array}{l}\text { Taxistas y conductores de } \\
\text { automóviles y furgonetas }\end{array}$ & 4,44 \\
\hline
\end{tabular}

\begin{tabular}{|l|c|}
\hline \multicolumn{2}{|c|}{ 2011TI-2018TI } \\
\hline Peones agrícolas & 53,59 \\
\hline Empleados domésticos & 12,98 \\
\hline Pintores, empapeladores y afines & 12,05 \\
\hline $\begin{array}{l}\text { Otros trabajadores de las obras } \\
\text { estructurales de construcción }\end{array}$ & 10,71 \\
\hline $\begin{array}{l}\text { Trabajadores cualificados en } \\
\text { huertas, invernaderos, viveros y } \\
\text { jardines }\end{array}$ & 9,87 \\
\hline
\end{tabular}




\begin{tabular}{|c|c|c|c|}
\hline \multicolumn{4}{|c|}{$\begin{array}{l}\text { Distribución relativa de las principales ocupaciones realizadas por los trabajadores varones en el } \\
\text { empleo doméstico Tipo 5. Promedio del periodo 2005TI-2018TI. Elaboración propia. Fuente: } \\
\text { microdatos EPA (INE). }\end{array}$} \\
\hline \multicolumn{2}{|l|}{ 2005TI-2010TIV } & \multicolumn{2}{|l|}{ 2011TI-2018TI } \\
\hline & CNO-94 & & CNO-11 \\
\hline Empleados del hogar & 60,92 & Empleados domésticos & 55,10 \\
\hline $\begin{array}{l}\text { Trabajadores que se dedican al } \\
\text { cuidado de personas y asimilados } \\
\text { (excepto auxiliares de enfermería) }\end{array}$ & 24,65 & $\begin{array}{l}\text { Trabajadores de los cuidados } \\
\text { personales a domicilio (excepto } \\
\text { cuidadores de niños) }\end{array}$ & 23,79 \\
\hline $\begin{array}{l}\text { Auxiliares de enfermería y } \\
\text { asimilados }\end{array}$ & 8,60 & $\begin{array}{l}\text { Trabajadores cualificados en } \\
\text { huertas, invernaderos, viveros } \\
\text { y jardines }\end{array}$ & 18,50 \\
\hline $\begin{array}{l}\text { Otros trabajadores de acabado de } \\
\text { construcción y asimilados }\end{array}$ & 2,97 & $\begin{array}{l}\text { Otros trabajadores de servicios } \\
\text { personales }\end{array}$ & 1,97 \\
\hline Peones de la construcción & 1,70 & & \\
\hline $\begin{array}{l}\text { Conserje de edificios, limpiacristales } \\
\text { y vigilantes }\end{array}$ & 1,16 & & \\
\hline
\end{tabular}

\section{CONCLUSIONES SUMARIAS.}

Una vez finalizado el estudio anterior, cabe sintetizar el mismo en las siguientes conclusiones:

- Paradójicamente, el empleo doméstico, en el agregado de sus diferentes variantes, poseyó una resistencia mayor a la recesión que el agregado de la economía. Sin embargo, sufre un colapso entre 2014 y 2015 -precisamente los años del inicio de la recuperación- que sólo comienza a revertirse, y muy lentamente, a partir de finales de 2017. Ello ha llevado a que su peso sobre el total de la ocupación haya caído de sus máximos del 4,08 y 4,04 en 2010 y 2013, respectivamente, al 3,4\% en 2018.

- El que éste sea un sector de actividad extraordinariamente informal ha conllevado que el porcentaje de ocupados del mismo dados de alta como afiliados en la Seguridad Social no haya superado nunca el 8\% del total. De hecho, la tendencia lentamente al alza en la integración en el sistema iniciada en 2007 -y que no sufrió ningún sock especial como consecuencia del cambio normativo de 2012- se detuvo a partir de 2015, comenzando entonces una ligera tendencia a la baja. Ello apunta a que tanto el nuevo y escaso empleo creado en el sector como parte del ya existente en el mismo está abandonando la cobertura del sistema.

- La otra gran característica del sector, cual es su drástico grado de feminización, se manifiesta en que los niveles de ocupación del mismo realizados por varones sólo 
hayan comenzado a notarse como consecuencia de la crisis económica, si bien sin superar el 15\% para el Tipo 1 ni apenas el 5\% para el tipo 2.

- A salvo del empleo Tipo 1 masculino, los estratos bajos de edad han perdido peso hasta la casi desaparición de los mismos en el sector en favor de los de edad más avanzada, lo que implica que el mismo ha podido ser receptor de trabajadoras que ya no se encontraban en activo pero que, ante la situación económica, y dada la posible experiencia en el mismo en etapas pasadas o, sencillamente, en sus hogares, han encontrado en éste una vía de ingresos.

- Otra nota característica del mismo es la fuerte presencia de trabajadores nacidos fuera de España, y ello especialmente en el empleo de Tipo 5 (internas), donde se acercaban a valores cercanos al 100\% hasta el inicio de la recesión. Para el tipo 1 (ordinario), la presencia de nacidos en el extranjero superaba el 50\%. En ambos casos se produce un aumento de la presencia de nacidos en España con el inicio de la crisis, es decir, que éste sector venía a ser visto en buena medida como subsidiario para los nacionales españoles hasta el recrudecimiento de la situación socioeconómica.

- En este sentido, la caída en la presencia de nacidos y nacidas fuera de España concurre en un periodo de reducción del empleo del conjunto del sector, es decir, que no cabe la hipótesis de que el peso de los trabajadores y trabajadoras extranjeros menguara por un incremento adicional de empleo ocupado por españoles adicional al que ellos representaban. En otras palabras, para numerosos puestos de trabajo se produjo una suerte de efecto sustitución de trabajadoras extranjeras por nacionales. Los principales países de origen de trabajadoras extranjeras para esta actividad son: Bolivia, Colombia, Ecuador, Flipinas, Honduras, Marruecos, Paraguay, Perú, Rep. Dominicana, Rumanía y Ucrania así como, además para el Tipo 5 (internas), Nicaragua

- En materia de capital humano de las trabajadoras del Tipo 1 (ordinario), destaca que las aquellas nacidas fuera de España poseen una formación mayor que las nacidas en España, pues para las primeras son casi paralelos los pesos de la "Educación obligatoria” y el "Bachillerato” mientras que, para las segundas, lo es, casi monopólicamente, el de la "Educación obligatoria”. Esta dinámica se repite, de manera muy similar, aunque con muchas mayor dificultades de medición dado el escaso número de nacidas españolas, para el Tipo 5 (internas).

- En materia de temporalidad, el principal contingente de empleo, es decir, las mujeres del Tipo 1, poseían de manera secular una tasa sustancialmente superior a la agregada que, sin embargo, terminó por confluir con ésta entre finales de 2015 y el inicio de 2016. El caso contrario se da para las trabajadoras del Tipo 5, las 
cuales, progresivamente, han ido alejándose de la tasa general en el sentido un peso cada vez mayor del empleo indefinido.

- En cuanto al tipo de contrato temporal, variable que se ha constatado que sólo posee consistencia, por lo que se acaba de señalar, para las mujeres del Tipo 1, se aprecia un claro cambio de tendencia tras la promulgación de la nueva regulación de 2012, reduciéndose el peso de los contratos de “otro tipo" (probablemente ausencia de contrato) en favor de los verbales o, dicho de otra manera, que las nuevas obligaciones en materia de Seguridad Social se cumplieran mediante esta fórmula poco precisa y de difícil prueba, en vez de mediante una forma escrita y de mayor seguridad. Ello mostraría una vez más la aceptación a regañadientes de la normativa tuitiva estatal sobre estas trabajadoras, consideradas en muchos casos un factor de producción más en manos del empresario/a - cabeza de familia.

- Sí cabe señalar que, hasta 2014, ese continente principal Mujeres - Tipo 1, contratos en meses muy por debajo de la media del mercado de trabajo.

- Consecuentemente a todo lo anterior, estos niveles de rotación han tenido como consecuencia que la antigüedad ganada en el empleo doméstico sea muy inferior al promedio del mercado laboral. Ello es especialmente paradójico en el caso de las trabajadoras internas, ya que con las mismas puede llegar a terminar por trabarse cierta relación afectiva-emocional (algo que estaría fuertemente vinculado a su reducción en la tasa de temporalidad).

- En materia de tiempo de trabajo, las tasas de parcialidad del Tipo 1 -variable sin relevancia en el caso del empleo Tipo 5- es sustancialmente mayor en el caso de las mujeres respecto del mercado trabajo, hasta el punto de multiplicarla secularmente por 4 en el conjunto del periodo estudiado (en el caso de los hombres, llega a multiplicarlo por 2 en algunos puntos, pero con considerables irregularidades). Igualmente, los niveles de involuntariedad en la parcialidad son superiores a los del mercado de trabajo, y ello para ambos sexos.

- Destaca que, como ocurre en el conjunto del mercado de trabajo en relación a los trabajadores que sí son parciales “voluntarios”, las causas de esa voluntariedad son drásticamente diferentes según sexos: en el caso de los hombres, aumentar su capital humano (y ello a pesar de las fuertes irregularidades mostradas en el gráfico correspondiente dado el bajo número de los mismos), mientras que, en el caso de las mujeres, esa “voluntariedad” proviene de la asunción de cargas familiares.

- Igualmente, en materia de tiempos de trabajo, si bien el alto nivel de parcialidad de las trabajadoras Tipo 1 hace que éstas posean una jornada promedio inferior al promedio del mercado de trabajo, destaca que éste, para las trabajadoras internas, 
prácticamente lo duplica si bien con una ligera tendencia descendente. En ese sentido, al inicio de la serie histórica las jornadas laborales de las trabajadoras Tipo 5 que superaban las 40 horas semanales de trabajo efectivo superaban el 50\% de los casos, pasando a niveles de en torno al 20\% desde 2014.

- En materia de absentismo por incapacidad o accidente, la presencia del mismo es, en promedio, la mitad que para el conjunto del mercado de trabajo, destacando además, como desigualdad de género, un peso de los trabajadores Tipo 1 superior al que tienen dentro de esa tipología de empleo. En otras palabras, que las mujeres de la misma fórmula de empleo, ante el mismo tipo de contingencias, dejan de acudir en menor medida a su puesto de trabajo.

- En la distribución ocupacional, destaca que los trabajadores varones del empleo doméstico Tipo 1 tienen una dedicación a los cuidados y las actividades ordinarias de limpieza, estando dedicados esencialmente a actividades de mantenimiento, vigilancia y jardinería, es decir, menos penosas que el cuidado como tal de niños y/o personas dependientes así como la limpieza interna de los hogares, las cuales quedan en manos de las trabajadoras (y también de los varones cuando se trata de empleo Tipo 5, si bien ello es lógico en tanto son las actividades consustanciales a esa tipología de empleo doméstico). Igualmente, parecen incluirse trabajadores de la construcción por el mero hecho de ser contratados directamente por los hogares y que, sin embargo, deberían estar en otras divisiones de la CNAE (incrementándose aún más el grado de feminización real de este empleo). 